NBER WORKING PAPER SERIES

ESTIMATING TRENDS IN MALE EARNINGS VOLATILITY WITH THE PANEL STUDY OF INCOME DYNAMICS

\author{
Robert A. Moffitt \\ Sisi Zhang \\ Working Paper 27674 \\ http://www.nber.org/papers/w27674
NATIONAL BUREAU OF ECONOMIC RESEARCH
1050 Massachusetts Avenue
Cambridge, MA 02138

August 2020

The authors would like to thank Joseph Altonji for comments on a version presented at the 2019 AEA meetings as well as the participants of a July 2019 conference sponsored by Equitable Growth in Cambridge, Massachusetts for their comments. Comments from James Ziliak and Michael Carr are appreciated as well as input from the other team members on this joint project: John Abowd, Christopher Bollinger, Charles Hokayem, Kevin Mckinney, and Emily Wiemers. Assistance from David Johnson was also valuable. The views expressed herein are those of the authors and do not necessarily reflect the views of the National Bureau of Economic Research.

NBER working papers are circulated for discussion and comment purposes. They have not been peerreviewed or been subject to the review by the NBER Board of Directors that accompanies official NBER publications.

(C) 2020 by Robert A. Moffitt and Sisi Zhang. All rights reserved. Short sections of text, not to exceed two paragraphs, may be quoted without explicit permission provided that full credit, including $\odot$ notice, is given to the source. 
Estimating Trends in Male Earnings Volatility with the Panel Study of Income Dynamics

Robert A. Moffitt and Sisi Zhang

NBER Working Paper No. 27674

August 2020

JEL No. C23,J3

\begin{abstract}
$\underline{\text { ABSTRACT }}$
The possible existence of trends in volatility in the U.S. labor market has been an important issue in both labor economics and macroeconomics. The Panel Study of Income Dynamics (PSID) has been the workhorse data set used to estimate trends in earnings volatility at the individual level. Studies using the PSID have generally shown upward trends in volatility. However, trends estimated with the PSID conflict with those reported from some other survey and administrative data sets, many of which have shown flat or declining trends. This paper, which is part of a group project attempting to reconcile estimates across different data sets, presents new estimates of trends in male earnings volatility in the U.S. from 1970 to 2016 from the PSID, and addresses a number of concerns with the data that might lead its estimates to differ from those obtained in other data sets. The analysis shows that upward trends in male earnings volatility were concentrated in the 1970s and 1980s, and that trends after 1990 have been modest or even nonexistent, depending on whether volatility is expected to return to its mid-2000s level after jumping up in the Great Recession. Thus, volatility trends in the PSID are roughly consistent with those studies using other data sets which find flat volatility trends in the last three decades. Examinations of potential biases from unit nonresponse (i.e., attrition), item nonresponse (i.e., don't knows and refusals) and resulting imputation, and from a number of other features of the PSID that might affect its population representativeness show no evidence of significant bias from any of these factors. However, suggestive evidence that declines in volatility estimated in studies using administrative data may be a result of a larger left tail of earnings and of problematic trimming procedures used in those studies.
\end{abstract}

Robert A. Moffitt

Department of Economics

Johns Hopkins University

3400 North Charles Street

Baltimore, MD 21218

and IZA

and also NBER

moffitt@jhu.edu

Sisi Zhang

Institute for Economic and Social Research

Jinan University

601 Huangpu Ave West

Guangzhou, Guangdong, 510632

China

sisi.zhang@gmail.com 
The literature on labor market volatility is vast and touches on multiple areas of macroeconomics, household finance, labor economics, and overlaps between them. The classic study of permanent vs transitory components of income and their implications for consumption, saving, and the marginal propensity to consume is just one example (Friedman, 1957; Hall and Mishkin, 1982). On the micro level, this literature has spilled over into household finance, with its concern with liquidity constraints, ability to deal with income shocks, possible inadequacy of assets to deal with such shocks, and consequent inability to smooth consumption sufficiently (Carroll, 1997; Gourinchas and Parker, 2002). In labor economics, a literature going back to the 1960s and 1970s on sectoral models of the labor market, with one sector characterized by high wages and stable jobs and another characterized by low wages and unstable jobs, has reemerged in recent discussions of technological change and the decline of union and manufacturing jobs, since the latter generally are more stable than average (Taubman and Wachter, 1986; Katz and Autor, 1999). The impact of income uncertainty on investments in human capital, both educational and on-the-job, and on investments in children at young ages, has generated yet another discussion in labor economics as well (Levhari and Weiss, 1974; Carneiro and Ginja, 2016)

A priori, whether labor market volatility should be expected to have risen or fallen differs by perspective. On the one hand, the just-mentioned literature on structural change in the U.S. labor market suggests that earnings instability might have increased, at least for workers with medium or lower skills. Katz and Autor (1999), for example, in their review of the early 
literature on increasing earnings inequality, make the connection between rising earnings inequality and rising instability. Haider (2001) also explicitly draws a connection between growing earnings inequality and earnings instability. On the other hand, a prominent hypothesis in macroeconomics is that the 1980s ushered in a period known as the Great Moderation, reflected in declining levels of aggregate volatility (McConnell and Perez-Quiros, 2000). While there is no necessary connection between aggregate volatility and volatility at the micro level (as noted by Davis and Kahn, 2008, and Dynan et al., 2012), some macroeconomists argue that a lack of decline in individual earnings volatility matching the aggregate volatility decline is intuitively difficult to explain (Sabelhaus and Song, 2010). Consequently, there is no consensus on whether labor market volatility should be expected to have risen, fallen, or remained stable.

This paper is motivated by the empirical literature to date on this question, which has provided different answers seemingly because different data sets have given different results. The workhorse data set for estimating trends in individual earnings volatility in the U.S. has been the Panel Study of Income Dynamics (PSID), a longitudinal survey that has been ongoing since 1968 (and hence the longest-running general-purpose socioeconomic panel in the world), which has attempted to maintain reasonable population representativeness and which asks extensive questions on labor market activity. The use of the PSID for the study of male earnings volatility began with Gottschalk and Moffitt (1994), who found male earnings volatility to have increased from 1970 to 1987, with the largest increases occurring among the less educated. About a dozen PSID studies subsequent to the Gottschalk-Moffitt study also found increases in male earnings volatility over time. ${ }^{1}$ However, no increase was found in at least one other panel

\footnotetext{
${ }^{1}$ See Dynarski and Gruber (1997), Haider (2001), Hyslop (2011), Keys (2008), Heathcote et al. (2010), Shin and Solon (2011), Dynan et al. (2012), Moffitt and Gottschalk (2012), Jensen and Shore (2015), and Carr and Wiemers
} 
survey, the Survey of Income and Program Participation (Celik et al., 2012) and, possibly more important, no increase and sometimes a decline has been found in studies using administrative data from Social Security or Unemployment Insurance records (Sabelhaus and Song, 2010; Dahl et al., 2011; Celik et al.,2012; DeBacker et al., 2013; Guvenen et al., 2014; Bloom et al., 2017). The difference in trends found in administrative data, which are often presumed to be more accurate than survey data, suggests that there may be problems with the PSID survey data.

This paper is part of a group project aimed at reconciling the disparate results on trends in male earnings volatility using six different data sets, both survey and administrative. ${ }^{2}$ This specific paper provides benchmark results for the PSID, to be compared to the results using the other data sets in the other papers but using the same definitions of volatility, sample definitions, and empirical procedures. New PSID results are also reported, extending to more recent years of data which were not available in prior PSID studies. As the results will show, this turns out to be crucial because volatility increased during the Great Recession and the newly available data can show whether volatility is returning to trend. In addition, this paper conducts a series of examinations of the PSID data aimed at gauging the importance of attrition, of nonreporting and imputation of earnings in the survey data, and of a number of other threats to its population representativeness; and we also conduct a series of exercises explicitly comparing the PSID to other data sets whose estimated volatility trends differ.

The results of the analysis are fourfold. First, we find that increases in volatility are much stronger from the 1970s to the 1980s than later and that volatility since approximately 1990 has either grown slowly or not at all, with the ambiguity resulting from whether volatility will

(2018). A full listing of all studies, along with those using other data sets, can be found in Moffitt and Zhang (2018).

2 The other papers in the project are Carr et al. (2020), McKinney and Abowd (2020), and Ziliak et al. (2020). 
continue to decline after the Great Recession. The latest year of data we have, 2016, shows volatility to have almost, but not quite, returned to its mid-2000 level. With the interpretation that the PSID is returning to trend, the PSID is consistent with results from other data sets showing little or no increase in volatility since 1990. Second, we find that the pattern of volatility trends is similar across all levels of the cross-sectional earnings distribution, but that the volatility trends have been most pronounced in the tails of the distribution of earnings changes. Third, we find that neither attrition, imputation, nor other threats to the representativeness of the PSID are likely to be responsible for the patterns of volatility trends found in the data. Fourth, we find that differences in the volatility trends in the PSID and administrative data sets may be a result of differences in the size of the left tail of earnings and of possible differences in trimming methods.

The outline of the paper is as follows. Our first section briefly clarifies different definitions of volatility, how they relate to each other, and what definition we will use here. The second section reviews the PSID data set and what is known about errors in reporting and about threats to its population representativeness. The third section reports our main findings on trends in male earnings volatility, while the fourth section conducts a series of examinations of attrition, imputation, and other issues that might bias PSID estimates of volatility trends. The fifth section directly examines several possible differences with the findings of other data sets. A short summary concludes. 


\section{Measuring Volatility}

The intuitive notion of volatility is clear but it can be, and has been, defined in different ways in the literature. Intuitively, volatility is just some measure of dispersion in the rate of change over time for some variable $y$. With a panel data set consisting of individual observations on $y_{\text {it }}$ for observations $i=1, \ldots, N$ and $t=1, \ldots, T$, the degree of volatility is often measured simply by the cross-sectional variance (or some other measure of dispersion) of the change in $y$ between two time periods $t$ and $t+1$, e.g., the variance of $y_{i, t+1-}-y_{i t}$. Studies interested in whether volatility has risen or fallen over time estimate this variance at successive calendar time points to answer that question.

We shall use this definition of volatility in our work but emphasize that it is differentexcept in a special case-from the variance of the transitory component in a traditional permanent-transitory error components model. The special case in which they coincide is when $y_{i t}=\mu_{i}+v_{i t}$, with $\mu_{i}$ a traditional time-invariant permanent component and $v_{i t}$ a traditional transitory component, and with the two components distributed independently. With $v_{i t}$ i.i.d., one-half the variance of $y_{i, t+1-y_{i t}}$ equals the variance of $v_{i t}$. However, while this simple model is still the standard in textbooks, the earnings dynamics literature has long moved beyond it, most importantly by allowing the permanent component to change over time. Most often the change is represented by a random walk, but often alternatively by a random growth factor or some other evolutionary process. ${ }^{3}$ In the random walk case, with $y_{i t}=\mu_{i t}+v_{i t}$ and $\mu_{i, t+1}=\mu_{i t}+\omega_{i t}$, and with $\omega_{i t}$ distributed independently of $\mu_{i t}$ and of $v_{i t}$ at all $t$, the variance of $y_{i, t+1-y_{i t}}$ contains the random

\footnotetext{
${ }^{3}$ Hall and Mishkin (1982) were one of the first in the income dynamics literature to introduce a unit root in the permanent component into the micro data literature, followed by many more. Tables 1 and 2 in Moffitt and Zhang (2018) lists all the types of error component models of income and earnings dynamics that have been used in the literature, at least those using the PSID.
} 
walk variance in the permanent component as well as the transitory variance. ${ }^{4}$ We use the term “volatility” in our paper to mean gross volatility, composed of volatility in both the permanent and transitory components of an underlying error components model.

An additional issue needing brief discussion is that of a distinction between age and calendar time. Although our paper is concerned with trends in volatility over calendar years, the literature on life cycle earnings dynamics has made clear that there are strong patterns in volatility over the life cycle and therefore with respect to age. We are therefore interested in the

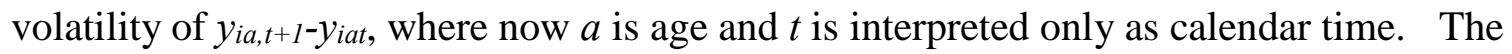
underlying error components model is $y_{\text {iat }}=\mu_{\text {iat }}+v_{\text {iat }}$. Calculating volatility with a single birth cohort followed over time could not separate life cycle volatility from calendar time volatility. The most common method of dealing with this issue is to use for $y_{i a t}$ the residuals of a regression of earnings on a function of age and thereby examine only volatility around a common ageearnings profile, although a profile that is allowed to shift with calendar time. This amounts to an assumption of a form of conditional independence between changes in age-specific and yearspecific volatility. We shall follow that procedure below, while also conducting some sensitivity tests to the assumption. ${ }^{5}$

\footnotetext{
${ }^{4}$ Serial correlation in the transitory component also leads to a different interpretation of the dispersion of changes in $y$. In fact, such correlation can create identification problems in these models, as should be obvious from the feature that both $\mu$ and $v$ are subscripted by $t$. For example, an ARMA specification for $v$ with unrestricted coefficients and variances - that is, with every lag length having its own coefficient and with the variance of the shocks nonparametric in $t$-leads to underidentification in a linear model because the entire autocovariance matrix of $y$ is accounted for by the transitory component, with nothing left for the permanent component (Moffitt and Zhang, 2018, Appendix). Most papers in the literature have chosen to impose restrictions on the $v_{i t}$ process in order to identify the dynamics of the permanent component process.

5 The PSID and many other panels refresh their cohorts and hence attempt to stay representative of the population over time. If, at each $t$, the observations in the data have the same age distribution, and if the parameters of the age-earnings profile are not changing, "aggregate” volatility taken over all ages will be the same weighted average of age-specific volatility in all calendar periods, and calendar trends will then be properly detected by changes in that volatility ignoring age.
} 


\section{The Panel Study of Income Dynamics}

The PSID is a longitudinal data set based on a representative sample of household units in the 1968 U.S. population. The members of the households and their descendants have been followed over time, and so-called "splitoff” families—mainly children who leave the family and form new households-are also followed, allowing the survey to stay reasonably representative of the U.S. population, unlike most cohort studies. The 1968 sample also included a low income oversample (the so-called "SEO" sample) but we exclude this sample in our analysis. We also exclude later Latino samples which were added to the survey in an attempt to address the exclusion of immigrants since 1968, an issue we examine below. We further exclude PSID “nonsample” members. ${ }^{6}$

Families were interviewed annually until 1996 and have been interviewed biannually since that year. ${ }^{7}$ Respondents are asked questions about the most recent calendar year's income, both for total family income and its components. The earnings components are separately identified only for household heads and their spouses and not for others in the household. The restriction to heads and spouses also opens up a possible difference with other data sets, which often include non-heads (and, in some administrative data sets, headship is not even identified). ${ }^{8}$ We use only wage and salary income and exclude self-employment earnings. We form a

\footnotetext{
${ }^{6}$ A PSID "sample member" is a person who was in the original sample in 1968 or who is a blood relation or descendant of an original sample individual. "Nonsample" members are anyone else. Since individuals who move into a family with a sample member, even if they were alive in 1968, are not necessarily a random sample of the population, excluding nonsample members makes our sample clearly defined as representative of the 1968 U.S. population.

${ }^{7}$ For this reason, we will look at 2-year volatility for all periods. See below.

8 There is fragmentary information on non-head earnings in the PSID for a few of the later years. We examined those data but because a different income concept was used, and for other reasons, we do not report analyses of them. However, the companion paper in this project on the CPS (Ziliak et al. (2020)) finds no differences in volatility trends for heads and non-heads.
} 
sample of male heads from interview year 1971 through interview year 2017, with our earnings measure therefore covering years 1970 to 2016.

Our baseline sample includes all male heads of family between the ages 25 and 59 in the interview year. We also keep only those who have positive wage income and positive weeks worked in each year (at least for our baseline sample; we will examine nonworkers in an alternative sample) and those who are not full-time students, and we necessarily exclude those who are not interviewed in a year, which means excluding individuals who have attrited. ${ }^{9}$ We work with residuals from regressions of the 2-year change in log earnings on a polynomial in age, all estimated separately by calendar year. We also trim the top and bottom one percent of the log earnings distribution each year (prior to the regression) to eliminate outliers which could distort our volatility measures. We will conduct sensitivity tests to many of these methods. This gives us an unbalanced panel with 3,975 men and 44,429 person-year observations, for an average of 11.2 year-observations per person. Earnings are in 2010 dollars, deflated by the Personal Consumption Expenditure (PCE) index.

As with all survey data, response error in income and earnings reports is a cause for concern (Bound et al., 2001). The PSID data have never been matched to government administrative data on earnings to compare the two. However, matches of other surveys to administrative data have found differences in both directions—-survey reports typically have jobs and earnings reports that are missing from the administrative data as well as the other way around. In many cases, this seems to be because the administrative data are in error and do not, for a variety of reasons, pick up jobs and earnings that survey respondents report (Juhn and McCue, 2010;

\footnotetext{
${ }^{9}$ In the early years of the PSID, those who missed a year were not returned to the next year to ask if they would return to the survey. Later, the PSID changed its procedures and began recontacting those who had missed an interview, some of whom rejoined the survey. We include observations on such individuals who rejoined.
} 
Abraham et al., 2013; Abowd and Stinson, 2013). However, in the 1980s the PSID did conduct a study which administered the PSID questionnaire to a sample of workers at a plant whose true earnings were known from the company's records, and several papers have been published on the results (Rodgers et al., 1993; Bound et al., 1994; Pischke, 1995). They show high correlations between survey and administrative earnings reports (.78 to .89) but also that misreports are negatively correlated with true earnings (this has also been found for other surveyadministrative data matches, e.g., Gottschalk and Huynh (2010)). This implies that survey data should have smaller cross-sectional variances than administrative data. This typically is indeed the case, for earnings distributions from Social Security and UI earnings records usually have considerably larger variances than survey data, but there are other possible reasons for this (see Section V).

More relevant for present purposes is whether misreports of earnings affect the variance of year-to-year earnings changes. In their work using the PSID matched data, Rodgers et al. (1993) and Bound et al. (1994) found measurement errors to be positively correlated over time but mean-reverting (i.e., positive $\mathrm{AR}(1)$ coefficient less than one) and that the reliability ratio for changes in earnings was about .75, a relatively high number. Pischke (1995) estimated the impact of PSID measurement error on decompositions into permanent and transitory variance components, and found it to have little effect. ${ }^{10}$ Nevertheless, while the gross volatility measures used in this paper will undoubtedly contain measurement error, for an analysis of calendar time trends the relevant question is whether that error has changed over time. While there is no evidence for a general change in that error over time for the PSID, there is one

\footnotetext{
10 Without data from an outside data set to validate survey reports, measurement error cannot be nonparametrically identified from the variances of the error components in the models described in Section I. Some papers in the earnings dynamics literature have put specific parametric structures on measurement error (e.g., i.i.d. or low-order MA) to identify them, but these are arbitrary assumptions which cannot be tested against unrestricted alternatives.
} 
specific instance of a possible change in PSID data collection procedures that might have had an effect on volatility estimates, which we discuss below.

Another important issue with all panel data sets is the presence of attrition (“unit nonresponse") and potential bias arising from it. The PSID experienced significant nonresponse in its first year (about 12 percent) but year-to-year response rates since that time have been about 96 percent-98 percent every year, although they have fallen in recent years (Institute for Social Research, 2019). However, even small attrition rates per year can cumulate to large totals eventually and, by 1989, Fitzgerald et al. (1998a) estimated that cumulative attrition had risen to about 44 percent. Cumulative attrition rates can no longer be calculated from the PSID because its sample is composed of second and third generation individuals, and a cumulative attrition rate from 1968 would require estimating one or two generations of fertility rates for families who attrited in the early years. ${ }^{11}$

The key issue with attrition is whether it is ignorable for a particular variable of interest and hence whether the remaining data set is no longer representative of the population distribution for that variable. ${ }^{12}$ The perhaps surprising finding from studies of the PSID is that, despite its high cumulative attrition rate, cross-sectional distributions of earnings and income seem to still line up well with national distributions from the Current Population Survey (CPS) (Becketti et al., 1988; Fitzgerald et al., 1998a; Gouskova et al., 2010; McGonagle et al., 2012; Schoeni et al., 2013). Fitzgerald et al. (1998a) showed that this arose in part because much attrition is for idiosyncratic reasons uncorrelated with economic variables, but also because the nonignorable

\footnotetext{
${ }^{11}$ Somewhat related to this, there is a significant literature on the effect of attrition on the estimation of intergenerational income elasticities with the PSID (Fitzgerald et al., 1998b; Fitzgerald, 2011; Schoeni and Wiemers, 2015).

12 Wooldridge (2010, Chapter 19) has an extensive discussion of the basic econometrics of attrition and attrition bias.
} 
component arises mostly from a correlation of attrition with the transitory, not the permanent, income component. As a result, regression-to-the-mean effects lead to a return to representativeness in short order. However, for present purposes the question is whether attrition is correlated with earnings volatility, and here Fitzgerald et al. (1998a) also found that attrition propensities were positively correlated with past levels of earnings instability (and marital and residential instability as well). We examine the effect of attrition on our estimated volatility trends in Section IV.

In addition to attrition, a fraction of respondents in all surveys have missing data on specific variables because of do-not-know responses and refusals-to-answer, from implausible values indicating response error, and for other reasons (“item nonresponse”). Item nonresponse is typically higher for economic variables like earnings and income than for demographic variables. There is an enormous literature in survey methodology on item nonresponse (Groves et al., 2002) and a smaller literature on the key issue of whether item nonresponse is or is not ignorable for variables like income and earnings. Bollinger et al. (2019) have shown it not to be ignorable for the CPS, with nonresponse highest in both tails of the earnings distribution, and similar patterns appear for the Survey of Income and Program Participation (Chenevert et al., 2015). A related literature addresses the problems with the imputation procedures used in surveys to fill in the missing values, and methods which just impute on the basis of other observables cannot, by definition, address non-ignorable selection. The most common method that analysts use to address the issue is to estimate models with and without observations that are imputed even though, if selection is non-ignorable, both are biased.

The PSID has some item nonresponse for its earnings questions as well, and has conducted imputations for its entire length, with the exact method of imputation having varied somewhat 
over time, generally with growing sophistication and complexity. Current imputation procedures for income use a variety of imputation methods, depending on the type of income being imputed and using a different set of variables for each (Duffy, 2011). However, fortunately, while earnings nonresponse and imputation rates appear to be high and often rising in other survey data sets (as high as 45 percent in the CPS according to Bollinger et al. (2019) and as high as 49 percent in the SIPP according to Czajka and Denmead (2008)), they are quite low in the PSID, about 3-to-4 percent per year (Killewald et al., 2011). The lower nonresponse rate in the PSID may be a result of the long-standing and trusting relationships that respondents have developed with PSID interviewers over many years of interviewing. We examine the importance of imputation in Section IV.

We show the summary statistics of real earnings and 2-year difference in real earnings in Appendix Tables 1 and 2. Appendix Table 1 presents real mean earnings as well as five percentile points in the real earnings distribution and two measures of cross-sectional inequality (the variance of log earnings and the coefficient of variation) for each year. Real earnings increased over the entire sample period but experienced temporary declines in the 1980s and during the Great Recession, particularly in the lower portion of the distribution. Cross-sectional inequality increased on average, especially in those same time periods. Appendix Table 2 presents the same statistics for 2-year difference in real earnings, where we do not see an overall increasing trend in the mean of differences in earnings. However, the table suggests an increasing variance because the dollar gap between the percentiles of differences is gradually increasing over time. For example, the gap between the $10^{\text {th }}$ and $90^{\text {th }}$ percentile points is approximately $\$ 25,000$ in our first period, $1970-1972$, and $\$ 38,000$ in our last period, 2014-2016. We note for future reference that there is no necessary relationship between increasing cross- 
sectional variance and increasing variance of differences; cross-sectional inequality could increase without any change in volatility and volatility could increase without any change in cross-sectional inequality.

\section{Main Results}

We begin with our baseline model. Gross volatility is measured by the variance of residuals in 2-year differences in log earnings (although we have 1-year differences before 1996, we want to be consistent with the 2-year differences after 1996). As noted previously, we work with residuals by regressing the 2-year change in log earnings on age and age squared, after initially trimming the level of log real earnings by year, following the procedure initiated by Shin and Solon (2011) and followed by many subsequent papers. Then we calculate the variance of the residuals. We exclude any male who is either not present in both years in the data or who has zero earnings in either year, given our use of log earnings residuals (we will include nonworkers in a separate section below). The first value, in 1972 represents the variance of the difference in log earnings residuals between 1970 and 1972 and the last value, in 2016, represents the variance of the difference in log earnings residuals between 2014 and $2016 .{ }^{13}$

Figure 1 shows that the trend in gross volatility follows the same three-phase pattern found in much of the PSID literature (Moffitt and Zhang, 2018), rising from the 1970s to the mid1980s, exhibiting a stable trend around significant fluctuations from the mid-1980s to the mid2000s, and rising thereafter. The dotted line in Figure 1 is a fit of the data to a $5^{\text {th }}$ order polynomial, which shows the three phases of the change more visibly. The figure also shows

\footnotetext{
13 In Figure 1, we interpolate the volatility estimates between pairs of years after 1996 to be able to draw a continuous line.
} 
the unemployment rate, demonstrating that volatility exhibits strong countercyclicality, although, on average, volatility only falls in a recovery period after a lag. But despite the countercyclicality of volatility, it did not return to its pre-downturn value in the late 1980s and it also rose in the mid-2000s when the unemployment rate was dropping prior to the Great Recession.

Two aspects of these basic results are worth noting. One is that there appears to be a difference in the trend prior to the early 1990s and afterwards-specifically, a close inspection of the figures appears to show a weaker trend afterwards. This has already been suggested by the declines in volatility that we have noted. However, it is difficult to see this pattern because of the period-to-period movements, so we illustrate these trends by normalizing volatility first to the average of 1972-1976 values and then to the average of $1992-96$ values. ${ }^{14}$ Figure 2a shows the trend in volatility when normalizing to $1972-1976$ and Figure $2 \mathrm{~b}$ shows the trend when normalizing to 1992-1996. Volatility rose by about 150 percent from the early 1970s to the early 1990s, but volatility ended up in 2016 only about 12 percent higher than it had been in the early 1990s. Thus, the evidence that the upward trend in volatility was much greater from the 1970 s to the 1980 s than it has been anytime since then is quite strong.

The other aspect of Figure 1 to note is that the rise in volatility starting in 2008 is no doubt related to the Great Recession and, in fact, the extra years that are now available from the PSID show that volatility continues to fall, including using the most recent data point 2014-2016. By 2014-2016, it had fallen to its value just prior to the Recession. While another year of PSID is

\footnotetext{
${ }^{14}$ We do not normalize to the exact initial year, 1972, or any single year in the early 1990s, because the values bounce around in those periods-especially the 1990s. Using an average over 5 years avoids the distortion created by normalizing to a single year.
} 
needed to determine whether this movement will continue, it is possible that it will continue to fall further, which would make the growth rate of volatility post-1990s even lower.

As we noted previously, there is one instance of a change in PSID data collection procedures that could have affected the measured volatility estimates in the 1990s, which were quite uneven (i.e., a large jump from 1990 to 1994 and a sharp decline thereafter). In the 1990s, the PSID made two important changes in data collection and editing procedures: one was a change from conventional telephone interviewing to computer-assisted telephone interviewing (CATI), and the other was a change in methods of editing the data for outliers (Kim and Stafford, 2000; Kim et al., 2000). The change to CATI not only changed the way of collecting the data but also changed the order, sequence, and method of asking income amounts. As noted previously by Dynan et al. (2012), there appear to be a large number of outliers in earnings differences in the 1990s, more than previously or afterwards. Our sample shows the same issue, with above average numbers of upward and downward changes in earnings in that period. To the extent that these changes in data collection procedures affected volatility in that period in particular, true volatility in the 1990s may be smoother than it appears in the data (indeed, the 2000 value in Figure 1 is about equal to its 1990 value).

We further explore the source of the increases in volatility within the distribution of earnings changes in two ways. First, we examine the percentile points of the distribution of the 2-year difference in log earnings residuals. One advantage of this exercise (which is common in the literature) is that it shows whether the average trend is stronger in some percentile points of the distribution than in others. Another advantage of this measure, compared to the variance, is that it reduces any dependence of the estimate of average volatility on outliers which, despite the trimming we conduct, could still be present. Appendix Figures 1, 2a, and 2b show the results. 
Increasing volatility reflects a widening out at all percentile points but with the largest widening occurring at the top and bottom of the change distribution. Further, after 2012 the gap between the top and bottom of the change distribution starts to narrow down. Appendix Figures 2a and $2 \mathrm{~b}$ suggest that the same difference in growth in the two periods found in average volatility are also found in the percentile points of the distribution of the 2-year difference log earnings residuals.

Second, we examine whether volatility trended differently in different parts of the crosssectional distribution. In addition to its inherent interest, this issue relates to whether shifts in the cross-sectional distribution of earnings will by itself affect average volatility trends, which are a weighted average of trends in volatility in different parts of that distribution. For this exercise we calculate volatility trends for separate cross-sectional earnings quartiles. ${ }^{15}$ Appendix Figure 3 shows the unnormed and actual values of volatility within each quartile, with the results implying that volatility is much higher in the bottom quartile than in the others but also that volatility in the three upper quartiles is approximately the same. The issue we are most concerned with is trends, and these are instead illustrated in Figures 3 for each quartile normed by its own mean over the entire observation period. Overall, the upward trend in volatility appears for all four quartiles, even though with more cyclicality at the bottom than at the top. In addition, while volatility in all four quartiles began at about 40 percent of its mean, the volatility for the bottom quartile ended up about 40 percent above its mean value while that

\footnotetext{
15 We use the quartile points of real earnings in a middle year-2000_-and group the observations in each pair of years by the location of those points in the middle year. One issue created by this approach is that, because real earnings inequality is increasing over time in the PSID (see above), a larger and larger fraction of the sample is in the upper and lower quartiles over time when constant real quartile boundaries are used. However, using year-byyear quartile boundaries produces approximately the same results (available upon request). We note that the other papers in this project (CPS, SIPP, and LEHD) estimated volatility using the cross-sectional PSID earnings distribution; those "permutations" tested the use of both time-varying and constant real percentile points of the PSID earnings distribution.
} 
for the other quartiles ends up about 20 percent above their respective means. However, these differences are slight relative to the communality of the average upward trend. ${ }^{16}$

Including nonworkers. Most studies in the literature on the volatility of male earnings exclude nonworkers, who have zero annual earnings. Our PSID sample of prime-age male workers has mean employment rates of over 85 percent in every year, a high figure compared to most other demographic groups, although the rate has been dropping over time, consistent with other research showing declining employment among U.S. men. However, while including nonworkers will almost certainly raise the level of volatility—because movements to and from zero earnings and a positive level will be larger than most movements of worker earningswhether it will affect trends in volatility depends on whether movements into or out of work (i.e., turnover rates) are changing over time. If employment levels drop but men simply stay out of work and do not reenter at higher rates, for example, volatility including nonworkers need not be higher than that for workers.

While addressing this issue could be accomplished by relatively formal econometric procedures—e.g., by specifying a separate dynamic process for the movement in and out of work and possibly accounting for selection into work on the basis of positive earnings volatility—we instead follow a simple procedure consistent with the transparent methods used throughout this paper. We capture volatility including nonworkers by using, instead of the variance of log earnings (which is not defined for nonworkers), the variance of arc percent change defined as ${ }^{17}$

\footnotetext{
${ }^{16}$ We estimated separate trends for those with a high school degree or less, and for those with at least some college. The lower educated group experienced somewhat similar trends to those of the bottom quartile: rising faster than the more educated group in the 1980s and in the Great Recession years, and ending up at a higher level relative to its mean in the final year, 2016.

17 This has been the measure used in the volatility literature when nonworkers have been included (Dahl et al., 2011; Ziliak et al., 2011; Dynan et al., 2012). It also has been used in the firm dynamics literature (e.g., Davis et al., 1998). Note that the arc percent change still rules out zero earnings if an individual receives zero income in both years. Also, the absolute value terms in the denominator are unnecessary in this application because we are using real earnings levels, which are nonnegative.
} 


$$
\text { Volatility }_{t}=\operatorname{Var}\left\{\frac{y_{i t}-y_{i, t-2}}{\frac{\left|y_{i t}\right|+\left|y_{i, t-2}\right|}{2}}\right\}
$$

To be comparable with the baseline results, we calculate the variances of the residuals of a regression on individual arc percent changes (the term in curly brackets) on age and age squared. We first compare gross volatility measured by the variance of the arc percent change calculated only over workers to compare to the already-reported variance of 2-year differences in log earnings residuals to establish a proper comparison. As shown in the lower two lines in Figure 4, the arc percent change measure of volatility is lower than that shown by log earnings differences and has a somewhat flatter trend, but the same pattern of faster growth in the first two decades compared to the second two still appears. ${ }^{18}$ When zero incomes are included, as shown in the upper line, volatility is much higher in magnitude, for the reason noted above. However, the same upward trend in volatility over the entire period, and the same relative magnitudes over the first half and second half, are observed. ${ }^{19}$ This implies that movements into and out of work are working in approximate parallel with movements of earnings of workers. In addition, including movements into and out of work does not alter the finding of faster growth in the first half of our observation period compared to the second. ${ }^{20}$

\footnotetext{
18 The difference is a result of nonlinearities in the log transformation, on the one hand, and the linear transformation implicit in the arc percent change measure, on the other. For very large changes in log earnings, a discrete difference in two log values is always greater than the arc percent change for the same values. 19 There is a somewhat higher rate of growth of volatility when zeroes are included than when they are excluded. This is because there was an above-average increase in the number of individuals entering employment in the 1990s and prior to the Great Recession (results available upon request).

${ }^{20}$ See Appendix Figures 4a and 4b which show our now-familiar norming in the two separate periods. While volatility including nonworkers is higher in levels than when they are excluding, the rate of growth of volatility over time is lower when they are included. In fact, in the second half of the observation period, there is no growth at all in volatility, including them.
} 


\section{Examination of Issues with the PSID and Sensitivity Tests}

\section{A. Age-adjusting and Trimming}

We first show briefly that almost all of the age-adjusting and trimming methods we use in our basic results have no effect on our conclusions regarding volatility trends. In our basic results we computed volatility from the residuals of a regression of the change in log earnings on age and age squared, but volatility computed with the change in unadjusted log earnings shows the same trend (Appendix Figure 5). This implies that the age distribution of the sample is relatively fixed over time and that the age-earnings profile is relatively stationary as well. Likewise, whether we conduct our trim at the $1 \% / 99 \%$ on log earnings by year (as we do in the basic results) or on the residuals from the log earnings change-age regression has no effect on volatility trends (Appendix Figure 5).

As for trimming itself, we emphasize that our trimming is conducted solely to reduce meansquared error by reducing the variance of our volatility estimates, while admitting bias. Trimming is not a solution to general measurement error-which occurs throughout the distribution-as noted by Bollinger and Chandra (2005). ${ }^{21}$ As shown in Appendix Figure 6, not doing any trimming at all, or trimming at the 5\%/95\% level instead, has no effect on the main trend patterns; those alternatives just introduce more or less noise in the year-by-year movements. $^{22}$

\section{B. Attrition}

\footnotetext{
21 Indeed, there is no presumption that the observations in the tails are mismeasured at all. But if there is measurement error, we should note, as we did in Section II, that stationary measurement error may have little effect on the time trends in volatility which are our central focus.

22 Of course, the scale of Appendix Figure 6 could be adjusted to see the trends for the 5/95 trim more clearly.
} 
We conduct an examination of possible attrition bias by examining whether attrition is related to observables that are correlated with earnings volatility. We make no attempt to correct for possible bias from selection on contemporaneous unobservables affecting both current volatility and current attrition, as that would require either parametric restrictions on the unobservables or the availability of an instrument. We instead examine whether current attrition probabilities are related to three lagged observables for each individual that could be related to current volatility: their earnings in the previous period, their mean earnings over the past six years, and the standard deviation of their earnings over the past six years. We estimate an attrition probit in each year on the sample of those who were in the sample at the initial period (recognizing potential bias in that previous period sample).

Appendix Figure 7 shows the year-by-year "attrition” rates and unit nonresponse rates in our sample. We define "attrition" for our analysis sample to include individuals who do not work in the second year of each volatility calculation as well as individuals who are missing in the second year, thereby including movements out of work along with nonresponse to the survey (the solid line shows "attrition" rates and the dashed line shows nonresponse rates). It is the combined effect which is of relevance for potential bias in our volatility measures. The figure shows that attrition rates defined in this way were a bit below .10 in the 1970s, about .10 in the 1980s, then rose steadily after 1990, reaching a level above .15 at the height of the Great Recession. ${ }^{23}$ The nonresponse rate was much lower than this, but also rose over time, at least in the 1990s and then again during the Great Recession. ${ }^{24}$ The increase of the attrition rates is a result of both an increase in nonresponse rate as well as nonemployment.

\footnotetext{
${ }^{23}$ After 1996, the attrition rate is higher because the change from annual to biennial increases the likelihood of dropping out of the sample or changing employment status.

${ }^{24}$ PSID response rates can be found in Institute for Social Research (2019). In addition to our nonresponse rate being defined at the individual rather than family level, it is also defined as an individual who is in our analysis
} 
Appendix Figure 8 shows the year-by-year coefficients on the three variables in the attrition probits. The probit coefficients on the lagged earnings and lagged mean earnings variables fluctuate around zero while the coefficient on the lagged standard deviation is positive but declining over time, implying that past earnings instability is a far more important influence of attrition than the level of earnings (even if its importance is falling). ${ }^{25}$ We show the effect of this attrition on our estimated volatility trends by predicting response probabilities (i.e., one minus the attrition probability) for each individual for each log-earnings-change observation in each pair of years, and applying inverse probability weighting to the volatility variance calculations. The results are shown in Figure 5. Attrition-adjusted volatility is higher in level than the unadjusted trend, which is expected since those with high (lagged) volatility are disproportionately missing from the responding sample. However, the gap grows over time because volatility—and hence lagged volatility—grows over time in the PSID and thus attrition adjustments make a larger difference in the 1980s and 2000s, when volatility grew the most. But the attrition-adjusted volatility in Figure 5 is very unstable, which is because there are a number of observations with very small weights arising from those with excessively high lagged volatility. Interestingly, when the bottom $1 \%$ of the weights is deleted, volatility levels and trends are close to those for unadjusted volatility, implying that attrition bias mainly arises from a small number of observations with high volatility. In any case, this analysis does not support attrition as a possible reason for the positive long-run trend in PSID volatility among male heads of household and, if anything, implies a stronger upward trend.

\footnotetext{
sample in the first year and is not followed in the PSID survey in the second year. That makes it slightly different from the response rates in the previously referenced document, which excludes deaths and unfollowed residential moves and includes recontact.

25 The probit coefficients on lagged earnings and lagged mean earnings are statistically insignificant at the 10 percent level for most years (results available upon request).
} 


\section{Imputation}

We briefly examine the potential of imputation in the PSID to affect our estimated volatility trends, using the conventional method of estimating those trends with and without the imputed observations included. Figure 6a shows the rates of imputation of earnings from 1970 to 2016 in our sample of male working heads, indicating that the percent of wage and salary income observations that are imputed ranges from a low of 0.30 to a high of 4.7, with the high value occurring in 1992, a period when the PSID changed its methodology and interviewing method (as discussed previously). While the low value of 0.30 is unlikely to change the results much, the higher value of 4.7 could if imputation is strongly correlated with volatility. But Figure 6b shows that estimated volatility trends with and without imputed observations included are very close to one another. This is unlikely to occur unless nonresponse is mostly ignorable. We conclude from this simple exercise that item nonresponse and imputation for earnings in the PSID is unlikely to be a reason for the greater upward trend in volatility compared to that in other data sets.

\section{Comparisons with results using other data sets}

In this section we explore three specific features of the PSID that could in principle potentially contribute to differences in estimated trends in volatility with other data sets: (1) partyear versus full-year workers, (2) differences in trimming methods and (3) differences in the coverage of immigrants. ${ }^{26}$

\footnotetext{
${ }^{26}$ Another possible difference with other studies is that the PSID earnings are mostly restricted to heads and spouses. The SIPP and CPS papers included as part of this project were able to address the issue of headship, and
} 


\section{A. Part-year workers}

As we noted previously, existing research which matches survey reports of earnings to administrative record data often finds errors going both ways (Juhn and McCue, 2010; Abraham et al., 2013; Abowd and Stinson, 2013). One of the differences appears to be that survey respondents often fail to report short, part-year jobs, especially if asked to recall earnings over the full prior calendar year, as the PSID and CPS do (but it also seems to be the case even for the SIPP, which has only a four-month recall period). ${ }^{27}$ Partly for this reason, several studies have found the administrative record data have a larger left tail of the earnings distribution than do survey data (Johnson and McCue, 2010; Kornfeld and Bloom, 1999; Spletzer, 2014; Abraham et al., 2013; Abowd et al., 2018). ${ }^{28}$ For present purposes, if the PSID is missing a portion of the left-tail of the earnings distribution — and if that tail has experienced a different trend in volatility than in the rest of the distribution —-this would generate differences in trends in average volatility between survey and administrative data.

We examine this issue by examining trends in PSID volatility separately for part-year and full-year workers and the levels and trends in the fractions of the sample that are part-year and

those papers find that the level of volatility is lower for heads but trends are the same as for non-heads. See [CPS and SIPP paper citations]. One other difference between some of the other data sets and our work is that we restrict our earnings measure to wage and salary earnings while some others use labor earnings, either fully or partly incorporating some types of self-employment income. We estimated volatility using PSID measures of labor earnings and found our trends largely unchanged, with labor income volatility rising slightly faster, not slower, in the second half of the observation period.

27 See Bound et al. (2001) for a detailed discussion of recall bias.

${ }^{28}$ See also Appendix Figure 5 of Bollinger et al. (2019), which shows that the residuals from Mincer regressions have a bigger left tail in administrative data than in survey data. The administrative data used in the other three studies in this project find this same pattern with their administrative data. 
full-year. We conduct a straightforward shift-share decomposition of PSID volatility trends into the share accounted for by changes in the share of part-year and full-year workers and the share accounted for by trends in volatility within each group. We define full-year as weeks worked over 48 weeks in the prior year and we also conduct robustness checks at 44 or 46 weeks cutoff. Let $y_{i t}$ be the change in individual $i$ 's earnings variable from $t$ - 1 to $t, i=1, \ldots N$, and that observations belong to groups $g=1,2, \ldots, G$ with $N_{g}$ observations in each group. Then the total variance, $\mathrm{V}$, can be decomposed as

$$
\begin{aligned}
\mathrm{V} & =\frac{1}{N} \sum_{g=1}^{g=G} \sum_{i=1}^{i=N_{g}}\left[\left(y_{i t}-\bar{y}_{g}\right)+\left(\bar{y}_{g}-\bar{y}\right)\right]^{2} \\
& =\sum_{g=1}^{g=G} \frac{N_{g}}{N}\left[\frac{1}{N_{g}} \sum_{i=1}^{i=N_{g}}\left(y_{i t}-\bar{y}_{g}\right)^{2}\right]+\sum_{g=1}^{g=G} \frac{N_{g}}{N}\left(\bar{y}_{g}-\bar{y}\right)^{2}
\end{aligned}
$$

which is the sum of the within-group variances weighted by their relative sizes in the sample and the weighted between-group variances. We divide our sample into four groups: full-year workers in both year $t-1$ and $t$, part-year workers in both year $t-1$ and $t$, full-year worker in $t-1$ and part-year worker in $t$, and part-year worker in $t-1$ and full-year worker in $t$. Thus $G$ is 4 .

Figure 7a shows the within group variances (in brackets) for workers who are full-year and part-year in both years and Figure 7b shows the values of $\mathrm{Ng} / \mathrm{N}$ for both groups. We do not show the results for the two change groups or for the between, as both are quite small and are dominated by the groups shown. Figure 7a shows that volatility of part-year workers is higher than that of full-year workers and grew faster in the early and later years of the observation period. However, Figure $7 \mathrm{~b}$ shows that the full-year workers are a larger fraction of the population than are part-year workers, and the sample composition became more composed of full-year workers and less composed of part-year workers between 1980 and 2000 (and after 
2000, both series experienced recession-induced cycles but the part-year cycle was sharper and fell to a lower level by then end of the recovery). Thus the within-group variances and the shares are moving in the opposite direction: part-year (full-year) shares are dropping (rising) but part-year (full-year) volatility is rising (falling).

The weighted sums of the two (that is, sum of the two terms in brackets multiplied by their respective values of $\mathrm{Ng} / \mathrm{N}$ ) are shown in Figure 7c, which indicates that the contribution of fullyear workers to overall volatility grew relative to that of part-year workers, at least on average, again after 1980. ${ }^{29}$ These results do not provide a clear expectation of what other data sets with different part-year/full-year compositions would find for average volatility. On the one hand, a data set with the same within-group variances but a higher share of part-time workers should be expected, on the basis of these results, to have higher average volatility. On the other hand, it is the changes in shares over time that matter for average PSID trends (and it is, again, the trends that matter for this paper), and its falling part-year shares end up making full-year workers a larger fraction of average volatility. Another data set with a smaller rise in full-year shares or a sharper drop in part-year shares, for example, could show flatter average volatility trends than those in the PSID.

\section{B. Trimming Method}

As we have discussed above, we trim on symmetric percentile points of the cross-sectional distribution in each year and show that our results on trends in volatility are not sensitive to the percentile points used. However, as noted by Carr and Wiemers (2020), several other studies in

\footnotetext{
${ }^{29}$ When we define full-year as weeks worked over 46 or 44 weeks, the proportion of part-year workers becomes smaller and the within group variances for part-year workers become larger. The trends on within-group variance, the fraction, and the weighted sum of the two, are similar to when we define full-year as weeks worked over 48 weeks. Results are available upon request.
} 
the literature using administrative data on Social Security earnings—all of which found, to varying degrees, declines in earnings volatility—used some version of real dollar trims to trim the bottom of their earnings distributions. Using real dollar trims is hazardous if earnings inequality is increasing, as it has for several decades in the U.S. and as it has in our PSID data set (Appendix Table 1). With earnings inequality growing, a constant real dollar trim will systematically exclude an increasing fraction of the lower tail of the earnings distribution (unlike a percentile point trim). If volatility levels are higher in the lower tail (as they are in the PSID), then deleting an increasing fraction of that tail will bias the trend in average volatility in a downward direction.

We follow Carr and Wiemers to test the effect of three different real dollar trimming methods employed by studies using Social Security earnings data. One excludes observations with real annual earnings below one quarter of full-time full-year work at the 2011 federal minimum wage, a method used by Kopczuk et al. (2010) (this is $\$ 3,685$ in our 2010 dollars). A second excludes observations with real annual earnings below a quarter of a year of full-time full-year work at half the federal minimum wage, but using the actual minimum in each year, a method used by Guvenen et al. (2014) and Bloom et al. (2017). A third excludes observations below the annual earnings need to qualify for the Social Security threshold for credit, a method used by Sabelhaus and Song (2009, 2010).

The results are shown in Figure 8a, which includes our baseline results for volatility trends as well and polynomial-smoothed lines are shown in Figure $8 b .{ }^{30}$ The first trimming method is significantly biased downward and has a much lower trend than the PSID, especially in the 1980s and after the year 2000. This is not surprising because it is the one method that uses a

${ }^{30}$ We retain a top $1 \%$ trim in all estimates and simply replace our baseline $1 \%$ bottom trim with each of the real dollar trims. 
constant real dollar trim, and the 1980s and 2000s are when earnings inequality at the bottom increased the most. On the other hand, the second method yields volatility trends close to those observed in the PSID and, in some periods, yields a slightly higher rate of growth than in the PSID, probably because the real minimum wage was falling over most years. The third method produces a downwardly-biased trend in volatility, as with the first method, even though the Social Security threshold tends to be raised to keep up with inflation. While none of our results produces a downward trend in volatility, the direction of bias is clear. The degree of bias could be larger in administrative data, which tend to have more part-year workers and a larger lower tail of the earnings distribution than the PSID.

\section{Immigrants}

The core PSID sample was representative of the 1968 U.S. population but therefore does not include those immigrating to the U.S. since 1968, who now constitute about 10 percent of the U.S. population. In 1990, about two thousand Latino households were added to the PSID which, though not representing all post-1968 migrants, represented an important migrant group of interest. But because of a lack of sufficient funding, the households were dropped after 1995. In 1997, a sample of 441 immigrant families was added to the PSID and another 70 immigrant families were added in 1999, for a total of 511 families. While the sample size is small, they have continued to be followed and their sample sizes have grown through childbearing and splitoffs. $^{31}$

We briefly analyze the volatility trends with and without this additional immigrant sample to determine whether there is any suggestion that the exclusion of immigrants might be

31 The PSID started a new attempt at an Immigrant Refresher sample in 2017. Not enough years are yet available to calculate volatility trends. 
contributing to upward PSID trends compared to those of other data sets which include immigrants. We compare our usual measure of gross volatility without the immigrant sample, with the immigrant sample, and on the immigrant sample only. Since the immigrant sample was only begun in income years 1996 or 1998, we start our analysis in 2000. Figure 9 shows the results. If anything, the volatility of the immigrant sample increases faster than that of the baseline sample, not slower. The volatility trend for the immigrant sample alone bounces around more, probably because of its smaller sample size. The gross volatility of the combined sample seems to increase slightly faster than the main sample after the late 2000s. Thus, while minimal, this evidence does not indicate a markedly slower growth of volatility for immigrants.

\section{Summary and Conclusions}

Understanding the evolution of micro earnings volatility in the U.S. labor market is important for research and for proper development of policies to address volatility. In light of conflicting evidence from different data sets and research papers on how that volatility has evolved, this paper has provided a new study of male earnings volatility from the workhorse data set in the literature, the Panel Study on Income Dynamics (PSID). We have provided updated estimates through the year 2016 —important because it provides information on recovery from the Great Recession—and we have examined a number of threats to the validity of PSID estimates related to issues of its data quality. We also conduct some limited but suggestive investigations on possible reasons for differences with other data sets in estimated volatility trends. 
We have four findings. First, contrary to reports that the PSID shows increasing volatility over the past five decades, we find that increases in volatility are primarily concentrated in the period from the 1970s to the 1980s. After approximately 1990, the rate of growth of volatility has been very slow and is approaching be zero if volatility continues to decline after the Great Recession, for it has already fallen back to its mid-2000 levels by 2016. The essentially flat trend could be interpreted as reflecting the Great Moderation in the sense that volatility has stopped growing, even though it has not declined. Second, we find that the pattern of volatility trends is similar across all levels of the cross-sectional earnings distribution, but that the volatility trends have been most pronounced in the tails of the distribution of earnings changes. Third, we find that neither attrition, imputation, nor other threats to the representativeness of the PSID are likely to be responsible for the patterns of volatility trends in the data. Fourth, we find that differences in the volatility trends in the PSID and in administrative data sets may be a result of differences in the size of the left tail of earnings, and may be a result of differences in trimming methods.

Going forward, more work on volatility among subgroups and decompositions would be warranted. More work on volatility among women, for example, is needed, and among those of different skill levels in the labor market. More work on decompositions of volatility into its three components--permanent, persistent (i.e., long lagged), and transitory (i.e., short lagged)—is warranted, as well as work on the relation of job and occupational mobility to earnings volatility. Data sets which match firms to workers would be valuable to ascertain the role of firms in worker earnings volatility, given much recent work on the importance of firms to the understanding of trends in labor market earnings (e.g., Song et al., 2019). 


\section{References}

Abowd, John M.; Kevin L. McKinney; and Nellie L. Zhao. 2018. "Earnings Inequality and Mobility Trends in the United States: Nationally Representative Estimates from Longitudinally Linked Employer-Employee Data.” Journal of Labor Economics 36: S183S300.

Abowd, John M., and Martha H. Stinson. 2013. Estimating Measurement Error in Annual Job Earnings: A Comparison of Survey and Administrative Data. Review of Economics and Statistics 95 (5):1451-67.

Abraham, Katherine G., John C. Haltiwanger, Kristin Sandusky, and James Spletzer. 2013. Exploring Differences in Employment between Household and Establishment Data. Journal of Labor Economics 31 (S1): 129-72.

Becketti, S.; W. Gould; L. Lillard; and F. Welch. 1988. “The Panel Study of Income Dynamics after Fourteen Years: An Evaluation.” Journal of Labor Economics 6: 472-92.

Bloom, Nicholas; Fatih Guvenen; Luigi Pistaferri; John Sabelhaus; Sergio Selgado; and Jae Song. 2017. “The Great Micro Moderation.” Working Paper.

Bollinger, Christopher and Amitabh Chandra. 2005. "Iatrogenic Specification Error: A Cautionary Tale of Data Cleaning.” Journal of Labor Economics 23(2): 235-57.

Bollinger, Christopher; Barry T. Hirsch; Charles M. Hokayem; and James P. Ziliak. 2019. "Trouble in the Tails? What We Know about Earnings Nonresponse Thirty Years after Lillard, Smith, and Welch.” Journal of Political Economy 127(5): 2143-85.

Bound, John, Charles Brown, Grey J. Duncan, and William L. Rodgers. 1994. Evidence on the Validity of Cross-sectional and Longitudinal Labor Market Data. Journal of Labor Economics, 12 (3): 345-68.

Bound, John; Charles Brown; and Nancy Mathiowetz. 2001. "Measurement Error in Survey Data.” In Handbook of Econometrics, Vol.5, eds. J.Heckman and J. Leamer. Amsterdam and New York: Elsevier North-Holland.

Carneiro, Pedro and Rita Ginja. 2016. "Partial Insurance and Investments in Children.” Economic Journal 126(October): F66-F95.

Carr, Michael D. and Emily E. Wiemers. 2018. New Evidence on Earnings Volatility in Survey and Administrative Data. American Economic Association Papers and Proceedings 108 (May): 287-91. 
Carr, Michael D. and Emily E. Wiermers. 2020. "The Role of Low Earnings in Differing Trends in Earnings Volatility.” Working Paper. Washington: Washington Center for Equitable Growth.

Carr. Michael D.; Robert A. Moffitt; and Emily E. Wiemers. 2020. "Reconciling Trends in Volatility: Evidence from the SIPP Survey and Administrative Data.” Working Paper. http://www.econ2.jhu.edu/people/moffitt/ES_MCRMEW_v9_2020-6-25.pdf (accessed $7 / 8 / 20)$

Carroll, Christopher D. 1997. "Buffer-Stock Saving and the Life Cycle/Permanent Income Hypothesis.” Quarterly Journal of Economics 112(1): 1-55.

Celik, Sule, Chinhui Juhn, Kristin McCue, and Jesse Thompson. 2012. Recent Trends in Earnings Volatility: Evidence from Survey and Administrative data. The B.E. Journal of Economic Analysis and Policy 12 (2).

Chenevert, Rebecca L.; Mark A. Klee; and Kelly R. Wilkin. 2015. "Do Imputed Earnings Earn Their Keep? Evaluating SIPP Earnings and Nonresponse with Administrative Records.” Washington: U.S. Census Bureau.

Czajka, John L. and Gabrielle Denmead. 2008. Income Data for Policy Analysis: A Comparative Assessment of Eight Surveys. Washington: Mathematica Policy Research.

Dahl, Molly, Thomas DeLeire, and Jonathan A. Schwabish. 2011. Estimates of Year-to-Year Volatility in Earnings and in Household Incomes from Administrative, Survey, and Matched Data. Journal of Human Resources 46 (4): 750-74.

Davis, Steven J.; John C. Haltiwanger; and Scott Schuh. 1998. Job Creation and Destruction. Cambridge: MIT Press.

Davis, Steven J. and James A. Kahn. 2008. "Interpreting the Great Moderation: Changes in the Volatility of Economic Activity at the Macro and Micro Levels.” Journal of Economic Perspectives 22(4): 155-80.

DeBacker, Jason Matthew, Bradley T. Heim, Vasia Panousi, Shanthi Ramnath, and Ivan Vidangos. 2013. Rising Inequality: Transitory or Permanent? New Evidence from a Panel of U.S. Tax Returns. Brookings Papers on Economic Activity 2013 (4): 67-142.

Duffy, Denise. 2011. 2007 PSID Income and Wage Imputation Methodology. Technical Series Paper \#11-03. Ann Arbor, Michigan.

Dynan, Karen, Douglas Elmendorf, and Daniel Sichel. 2012. The Evolution of Household Income Volatility. The B.E. Journal of Economic Analysis \& Policy 12 (2): 1-42.

Dynarski, Susan and Jonathan Gruber. 1997. Can Families Smooth Variable Earnings? Brookings Papers on Economic Activity 1997 (1):229-303. 
Fitzgerald John. 2011. Attrition in Models of Intergenerational Links in Health and Economic Status in the PSID. The B.E. Journal of Economic Analysis \& Policy Vol. 11: Issue 3 (Advances), Article 2

Fitzgerald, John, Peter Gottschalk, and Robert A. Moffitt. 1998a. An Analysis of Sample Attrition in Panel Data: The Michigan Panel Study of Income Dynamics. Journal of Human Resources 33 (2): 251-99.

Fitzgerald, John, Peter Gottschalk, and Robert A. Moffitt. 1998b. An Analysis of the Impact of Sample Attrition on the Second Generation of Respondents in the Michigan Panel Study of Income Dynamics. Journal of Human Resources 33 (2): 300-344.

Friedman, Milton. 1957. The Permanent Income Hypothesis. In A Theory of the Consumption Function, 20-37. Elizabeth: Princeton University Press.

Gottschalk, Peter and Minh Huynh. 2010. Are Earnings Inequality and Mobility Overstated? The impact of Nonclassical Measurement Error. Review of Economics and Statistics 92(2): 30215.

Gottschalk, Peter, and Robert Moffitt. 1994. The Growth of Earnings Instability in the U. S. Labor Market. Brookings Papers on Economic Activity 1994 (2): 217-72.

Gourinchas, Pierre-Olivier and Jonathan A. Parker. 2002. Consumption over the Life Cycle.” Econometrica 70(1): 47-89.

Gouskova, Elena; Patricia Andreski; and Robert F. Schoeni. 2010. “Comparing Estimates of Family Income in the Panel Study of Income Dynamics and the March Current Population Survey, 1968-2007.” http://psidonline.isr.umich.edu/Publications/Papers/tsp/201001_comparing_estimates_of_fam.pdf.

Groves, Robert M.; Don A. Dillman; John L. Eltinge; and Roderick J.A. Little, eds. 2002. Survey Nonresponse. New York: Wiley.

Guvenen, Fatih, Serdar Ozkan, and Jae Song. 2014. The Nature of Countercyclical Income Risk. Journal of Political Economy 122(3): 621-60.

Haider, Steven. 2001. "Earnings Instability and Earnings Inequality of Males in the United States, 1967-1991.” Journal of Labor Economics 19 (October): 799-836.

Hall, Robert E, and Frederic S Mishkin. 1982. The Sensitivity of Consumption to Transitory Income: Estimates from Panel Data on Households. Econometrica 50 (2): 461-81.

Heathcote, Jonathan; Kjetil Storesletten; and Giovanni L. Violante. 2010. “The Macroeconomic Implications of Rising Wage Inequality in the United States.” Journal of Political Economy 118 (August): 681-722. 
Hyslop, Dean R. 2001. Rising U.S. Earnings Inequality and Family Labor Supply: The Covariance Structure of Intrafamily Earnings. American Economic Review 91 (4): 755-77

Institute for Social Research, 2019. PSID Main Interview User Manual. Ann Arbor: Survey Research Center, University of Michigan. https://psidonline.isr.umich.edu/Guide/default.aspx (accessed 7/6/20).

Jensen, Shane T, and Stephen H Shore. 2015. Changes in the Distribution of Earnings Volatility. Journal of Human Resources 50 (3): 811-36.

Juhn, Chinhui and Kristin McCue. 2010. Comparing Measures of Earnings Instability Based on Survey and Administrative Reports. US Bureau Census for Economics Studies Paper CESWP-10-15.

Katz, Lawrence F. and David H. Autor, 1999. "Changes in the Wage Structure and Earnings Inequality.” In Handbook of Labor Economics, Vol. 3A, eds. O. Ashenfelter and D. Card. Amsterdam and New York: Elsevier North-Holland.

Keys, Ben. 2008. Trends in Income and Consumption Volatility, 1970-2000. In Income Volatility and Food Assistance in the United States, ed. D. Jolliffe and J. Ziliak. Kalamazoo, Mich: W.E. Upjohn Institute.

Killewald, Alexandra; Patricia Andreski; and Robert F. Schoeni. 2011. "Trends in Item Nonresponse in the PSID, 1968-2009.” Panel Study of Income Dynamics Technical Series Paper \#11-02. Ann Arbor, MI: Survey Research Center, University of Michigan.

Kim, Yong-Seong; Tecla. Loup; Joseph Lupton; and Frank P. Stafford. 2000. "Notes on the 'Income Plus’ Files: 1994-1997 Family Income and Component Files.” Institute for Social Research, University of Michigan.

Kim, Yong-Seong. and Frank P. Stafford. 2000. "The Quality of PSID Income Data in the 1990s and Beyond.” Ann Arbor: Institute for Social Research, University of Michigan.

Kopczuk, Wojciech, Emmanuel Saez, and Jae Song. 2010. "Earnings Inequality and Mobility in the United States: Evidence from Social Security Data since 1937.” Quarterly Journal of Economics 125 (Feb): 91-128

Kornfeld, Robert and Howard S. Bloom. 1999. "Measuring Program Impacts on Earnings and Employment: Do Unemployment Insurance Wage Reports from Employers Agree with Surveys of Individuals?” Journal of Labor Economics 17: 168-197.

Levhari, David and Yoram Weiss. 1974. "The Effect of Risk on the Investment in Human Capital.” American Economic Review 64(6): 950-963. 
McConnell, Margaret M. and Gabriel Perez-Quiros. 2000. "Output Fluctuations in the United States: What Has Changed since the Early 1980s?” American Economic Review 90(5): 1464-76.

McGonagle, Katherine A.; Robert F. Schoeni; Narayan Sastry; and Vicki A. Freedman. 2012. "The Panel Study of Income Dynamics: Overview, Recent Innovations, and Potential for Life Course Research.” Longitudinal Life Course Studies 3(2): 1-17.

McKinney, Kevin L. and John M. Abowd. 2020. "Male Earnings Volatility in LEHD Before, During, and After the Great Recession.” Working Paper.

Moffitt, Robert A. and Peter Gottschalk. 2012. Trends in the Transitory Variance of Male Earnings: Methods and Evidence. Journal of Human Resources 47(1): 204-36.

Moffitt, Robert A. and Sisi Zhang. 2018. "Income Volatility and the PSID: Past Research and New Results.” American Economic Association Papers and Proceedings 108 (May): 27780.

Pischke, Jörn-Steffen. 1995. Measurement Error and Earnings Dynamics: Some Estimates from the PSID Validation Study. Journal of Business \& Economic Statistics 13 (3): 305-14.

Rodgers, Willard L.; Charles Brown; and Greg J. Duncan. 1993. "Errors in Survey Reports of Earnings, Hours Worked, and Hourly Wages.” Journal of the American Statistical Association 88:1208-1218.

Sabelhaus, John and Jae Song. 2009. “Earnings Volatility Across Groups and Time.” National Tax Journal 62 (June): 347-364.

Sabelhaus, John, and Jae Song. 2010. The Great Moderation in Micro Labor Earnings. Journal of Monetary Economics 57 (4): 391-403.

Schoeni, Robert F.; Frank Stafford; Katherine A. McGonagle; and Patricia Andreski. 2013. "Response Rates in National Panel Surveys." Annals of the American Academy of Political and Social Science 645 (January): 60-87.

Schoeni, Robert F. and Emily E. Wiemers. 2015. "The Implications of Selective Attrition for Estimates of Intergenerational Elasticity of Family Income.” Journal of Economic Inequality 13:351-372.

Shin, Donggyun, and Gary Solon. 2011. Trends in Men’s Earnings Volatility: What Does the Panel Study of Income Dynamics Show? Journal of Public Economics 95 (7-8). Elsevier B.V.:973-82.

Song, Jae; David J. Price; Fatih Guvenen; Nicholas Bloom; and Till von Wachter. 2019. “Firming Up Inequality.” Quarterly Journal of Economics 134(1): 1-50.

Spletzer, James R. 2014. “Inequality Statistics from the LEHD.” Working Paper. Washington: U.S. Bureau of the Census. 
Taubman, Paul and Michael Wachter. 1986. "Segmented Labor Markets.” In Handbook of Labor Economics, Vol.2, eds. Orley Ashenfelter and Richard Layard. New York and Amsterdam: Elsevier North-Holland.

Wooldridge, Jeffrey M. 2010. Econometric Analysis of Cross Section and Panel Data. Cambridge: MIT Press.

Ziliak, James P., Bradley Hardy, and Christopher Bollinger. 2011. "Earnings Volatility in America: Evidence from Matched CPS.” Labour Economics 18(6): 742-54.

Ziliak, James P.; Charles Hokayem; and Christopher R. Bollinger. 2020. "Trends in Earnings Volatility using Linked Administrative and Survey Data.” Working Paper. http://ukcpr.org/sites/ukcpr/files/research-pdfs/DP2020-01.pdf (accessed 7/7/20). 


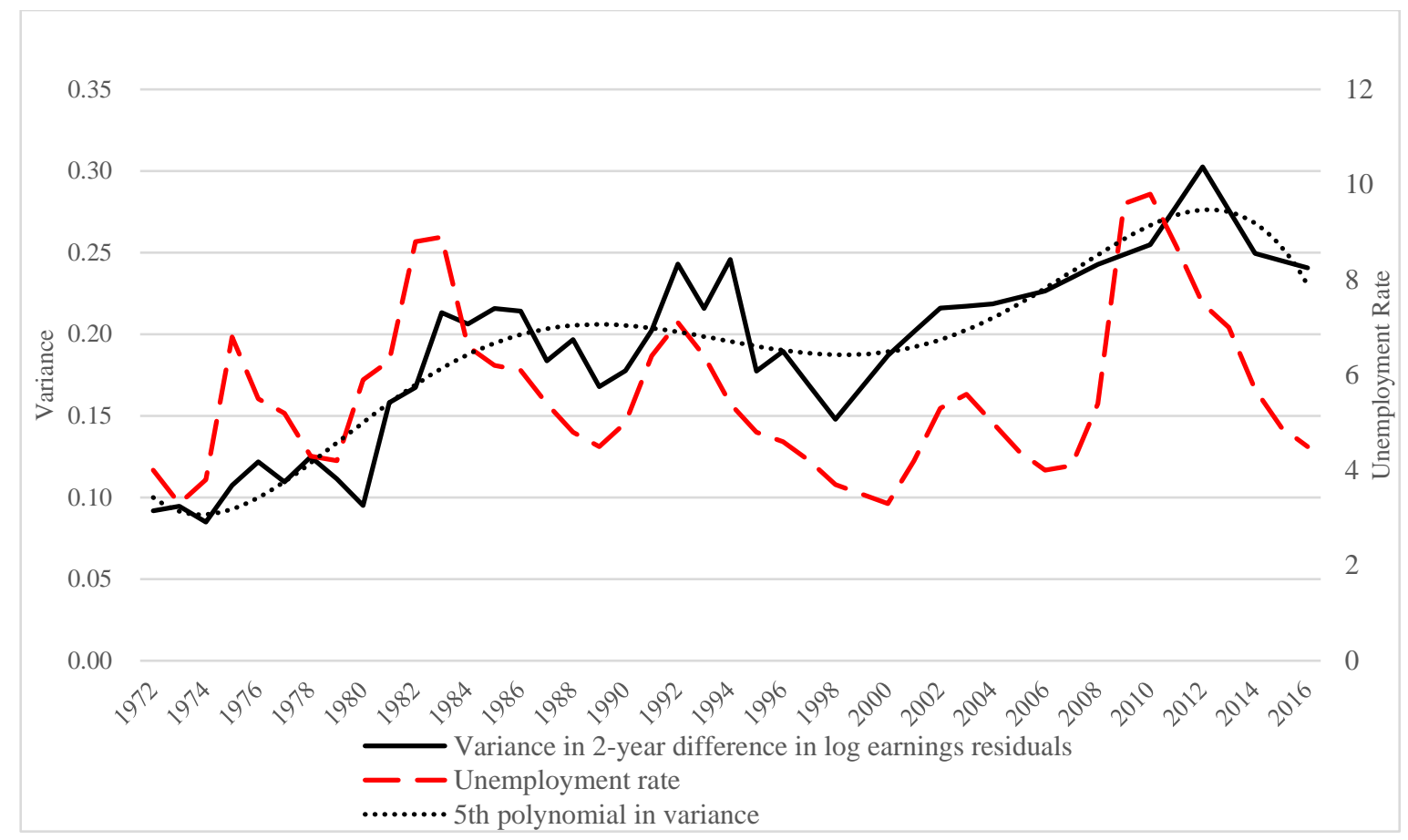

Figure 1: Variance in 2-year difference in log earnings residuals 


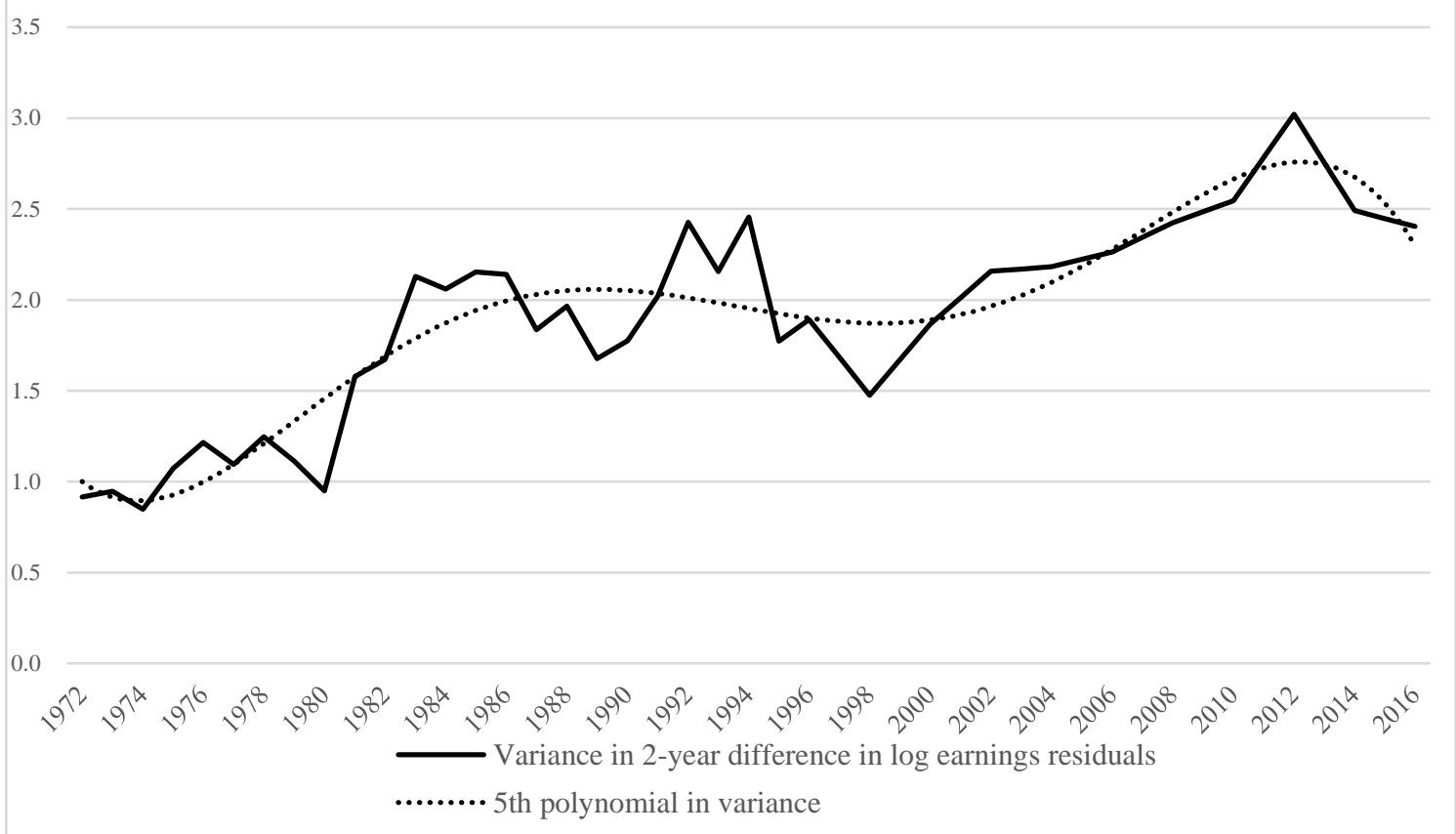

Figure 2a: Variance in 2-year difference in log earnings residuals, 1972-76=1

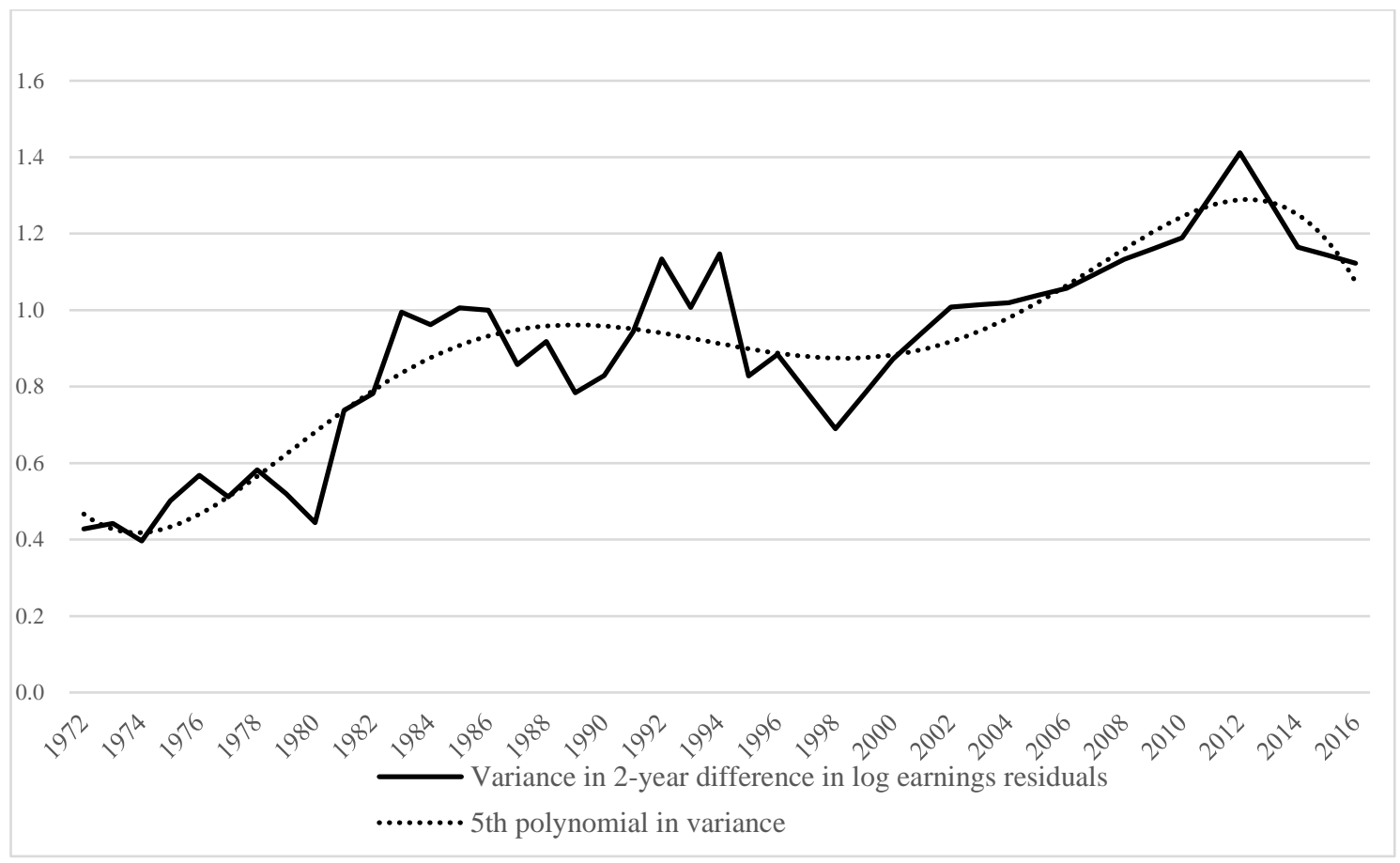

Figure 2b: Variance in 2-year difference in log earnings residuals, 1992-96=1 

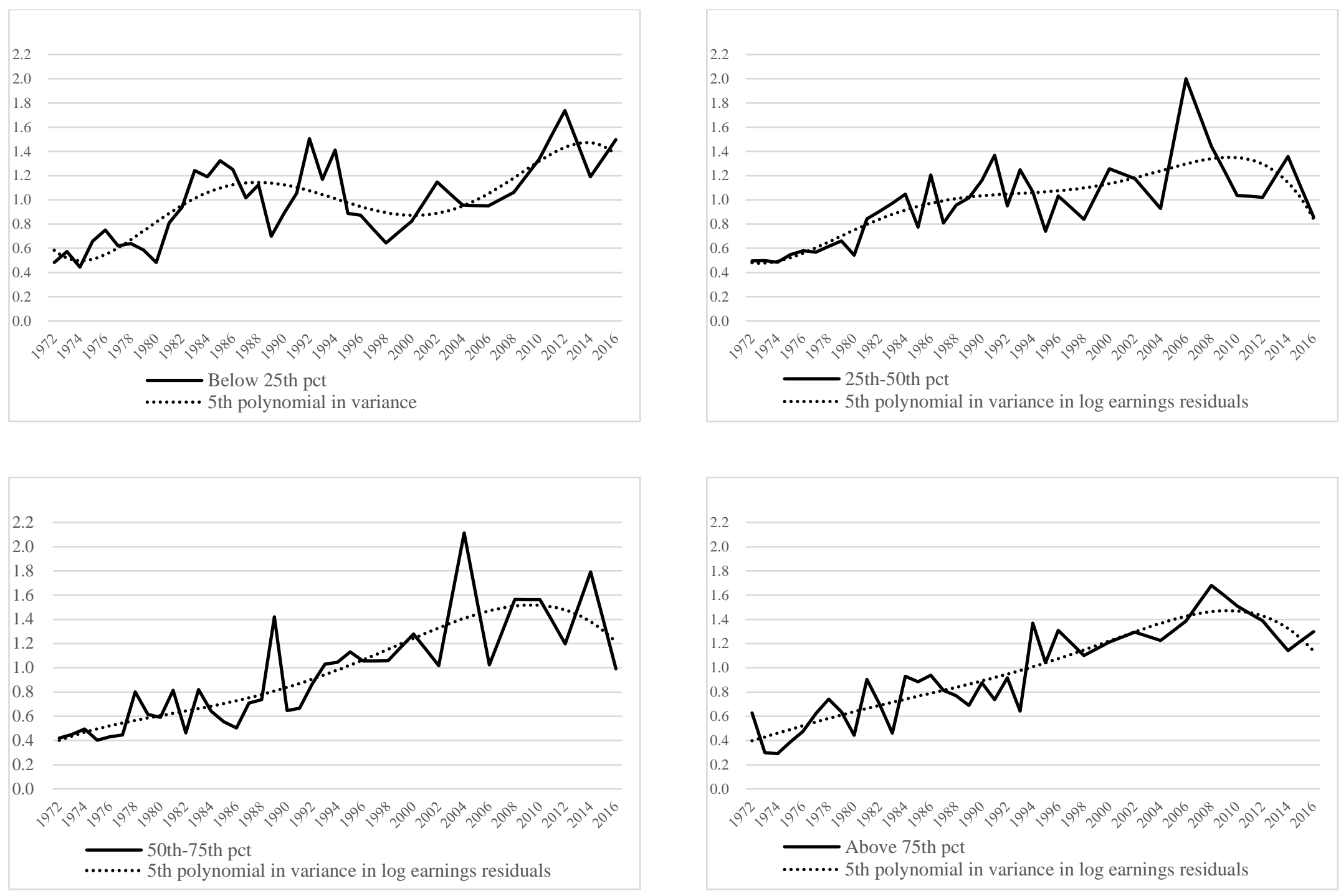

Figure 3: Variance in 2-year difference in log real earnings by quartile, normalized by average over all years 


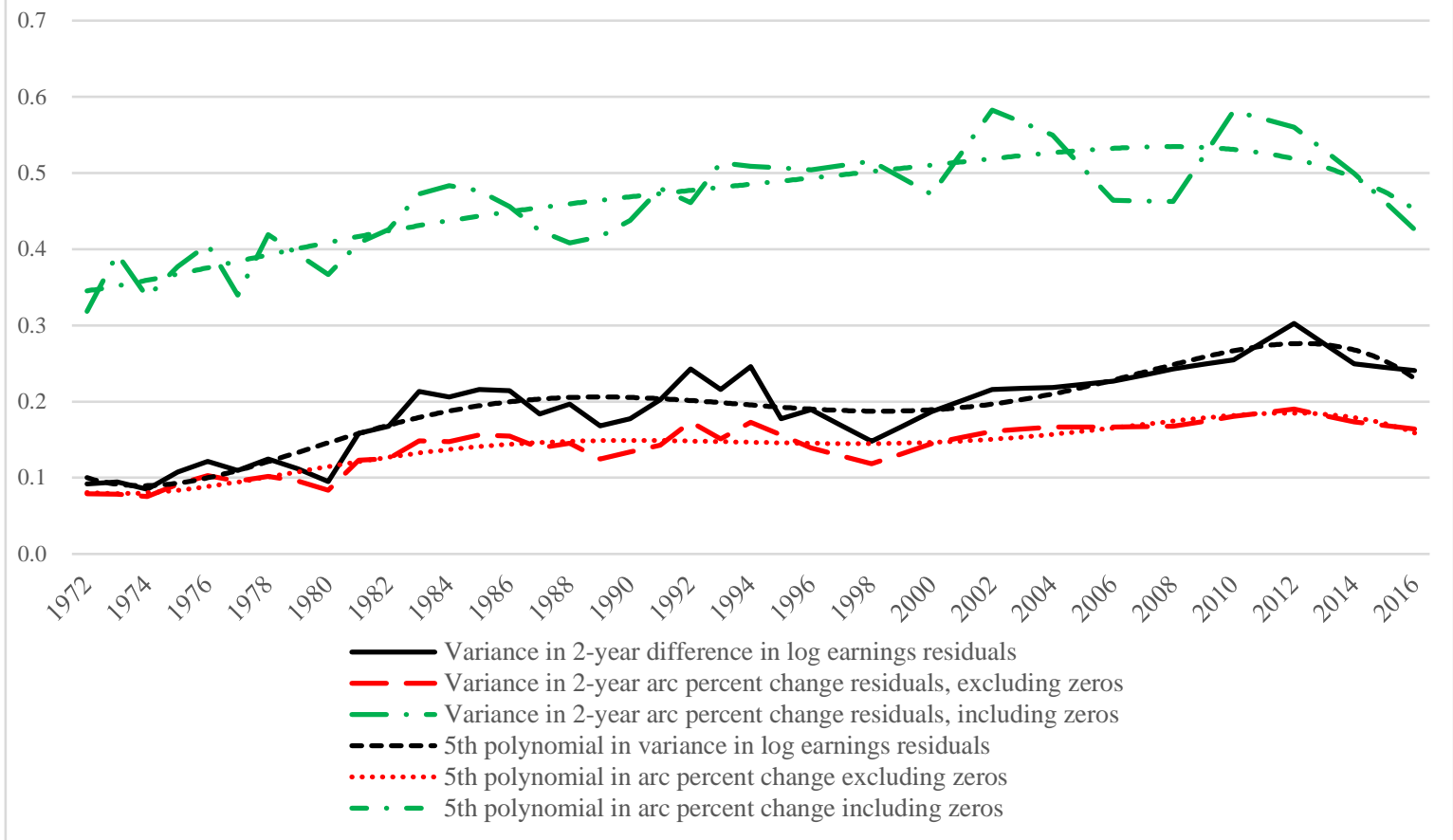

Figure 4: Variance in 2-year difference in log earnings residuals, arc percent change excluding zeros, and arc percent change including zeros

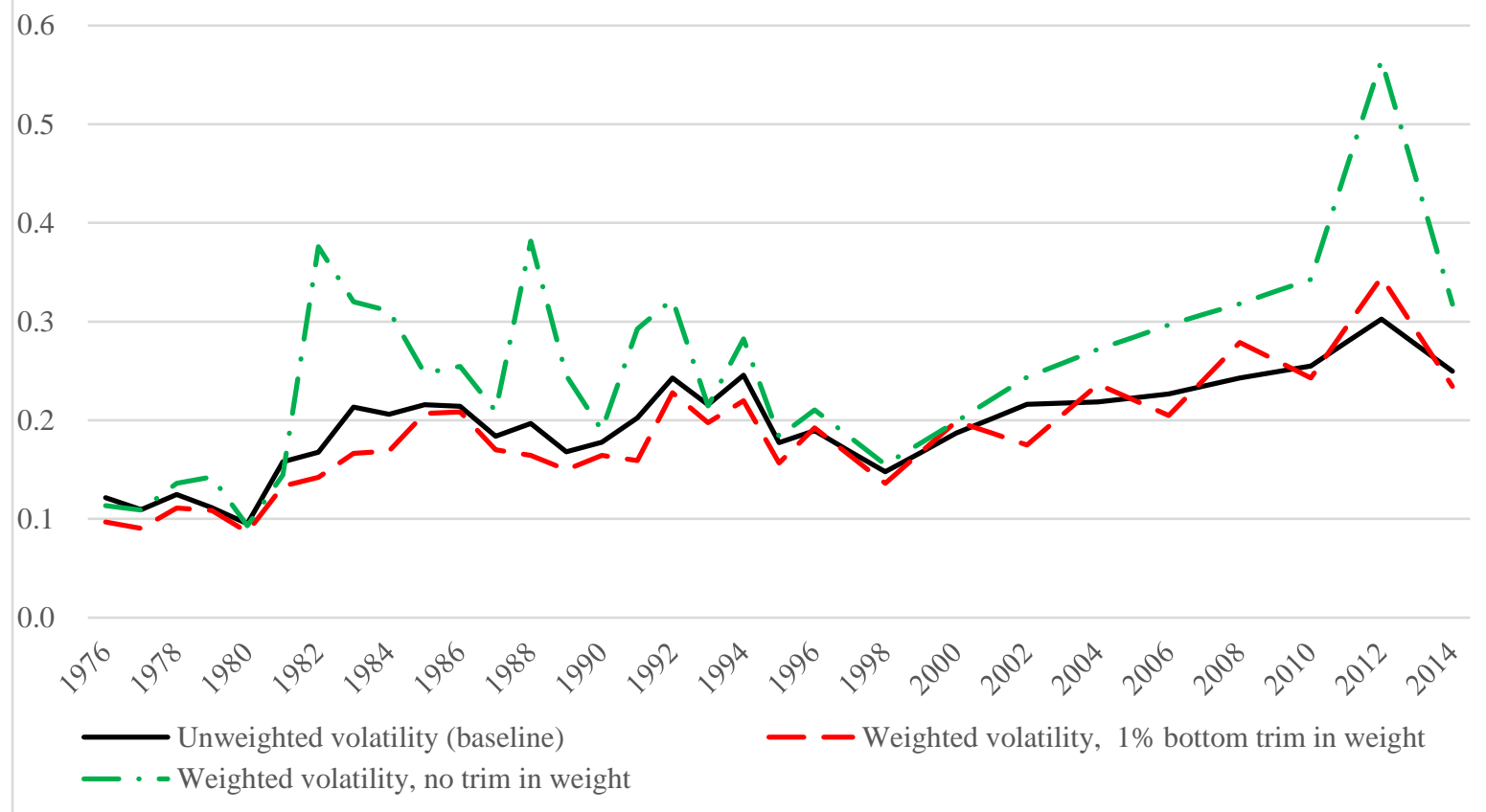

Figure 5: Volatility reweighted by inverse attrition probability vs. baseline volatility 


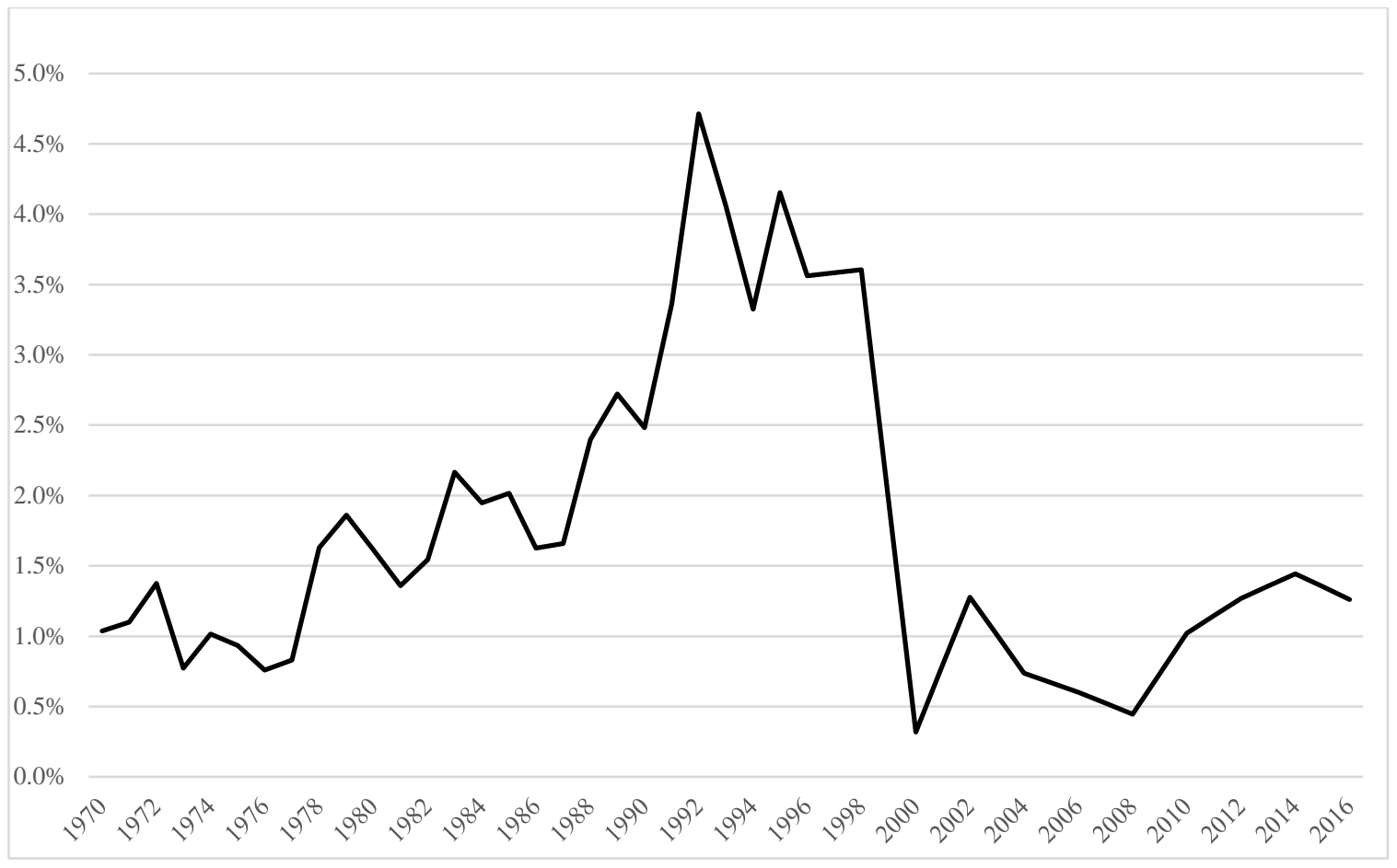

Figure Ga: Rates of imputation of earnings

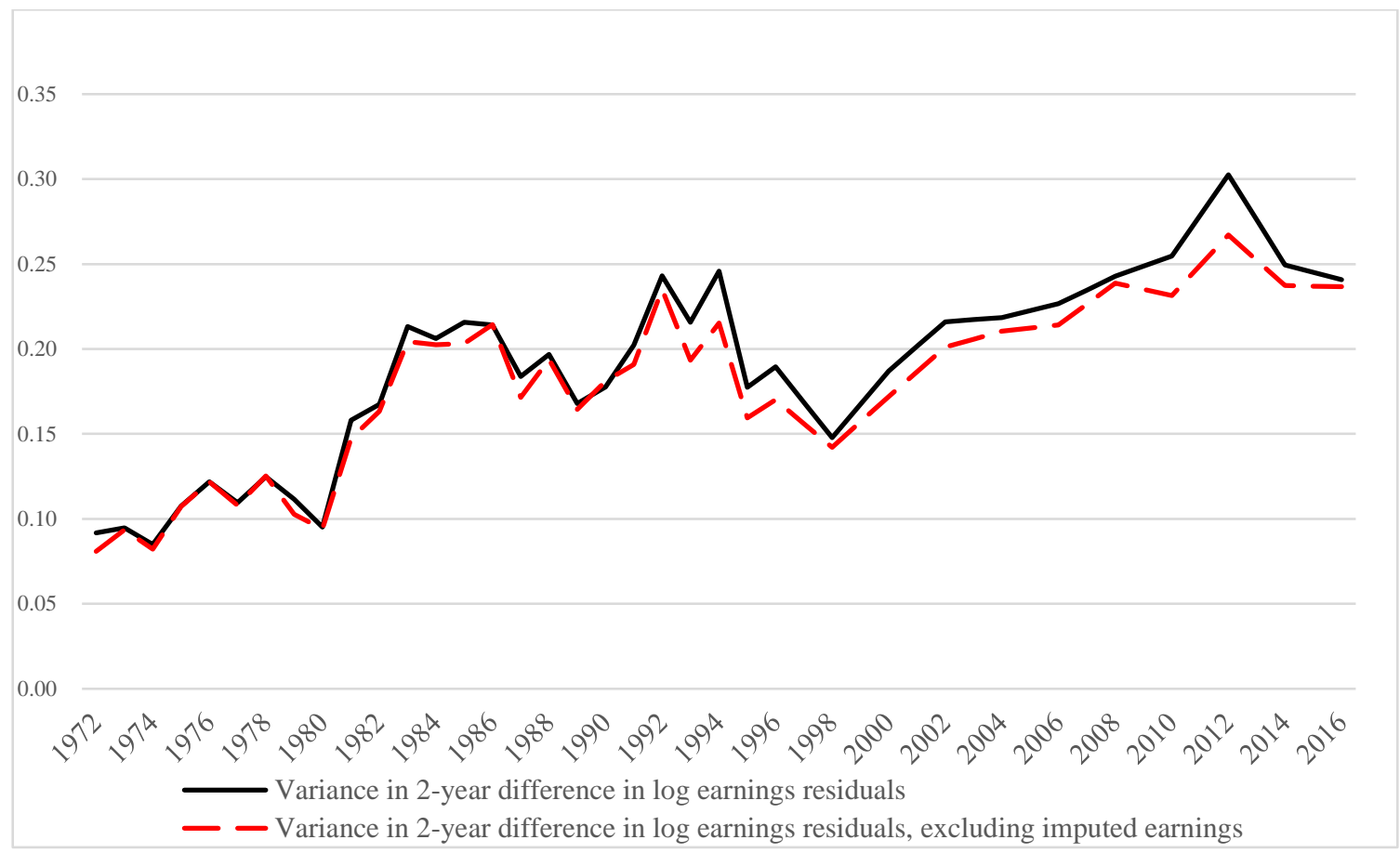

Figure Gb: Variance of 2-year difference of log earnings residuals, main sample and excluding imputed earnings

41 


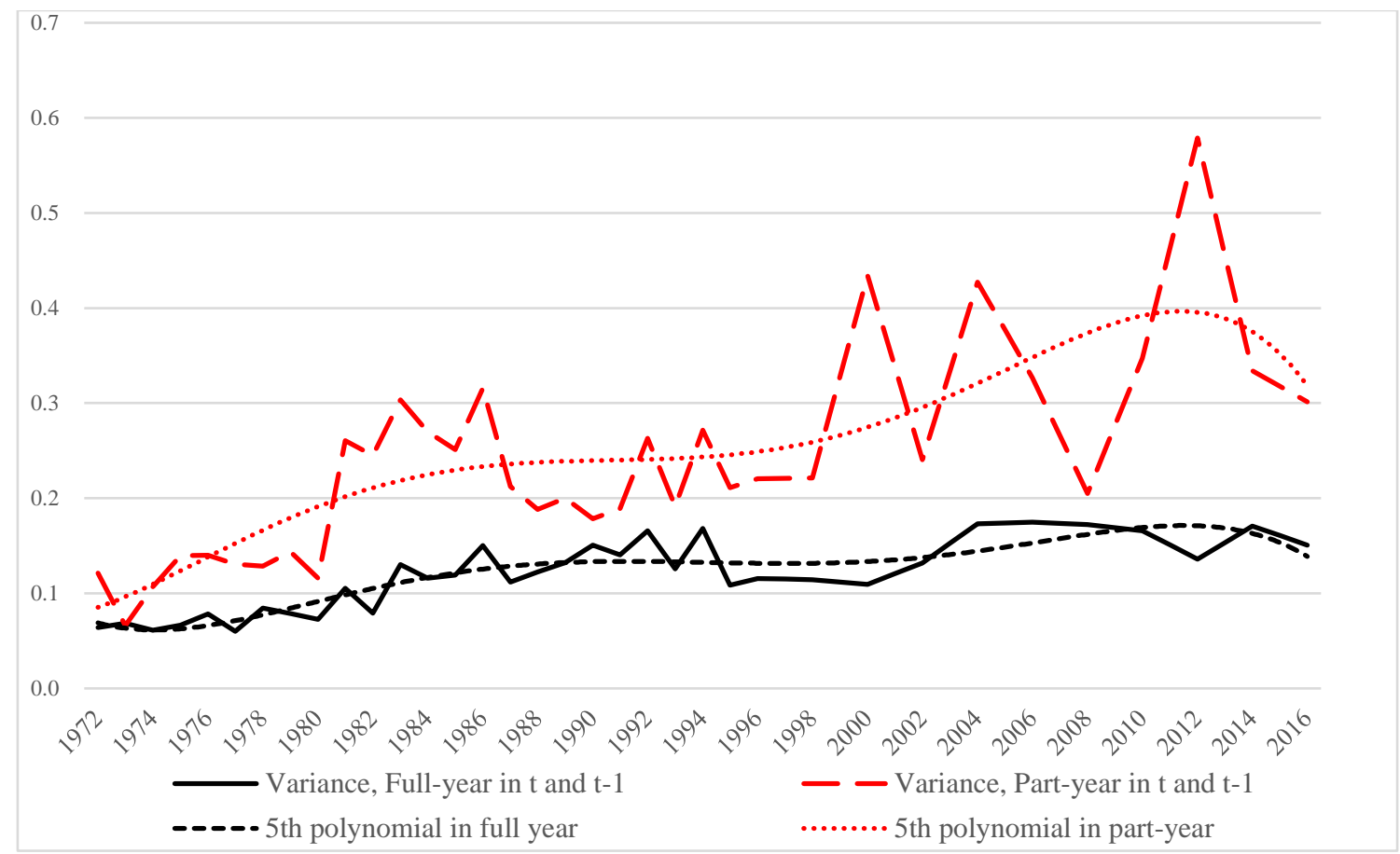

Figure 7a: Within group variance for workers who are full-year and part-year in both years

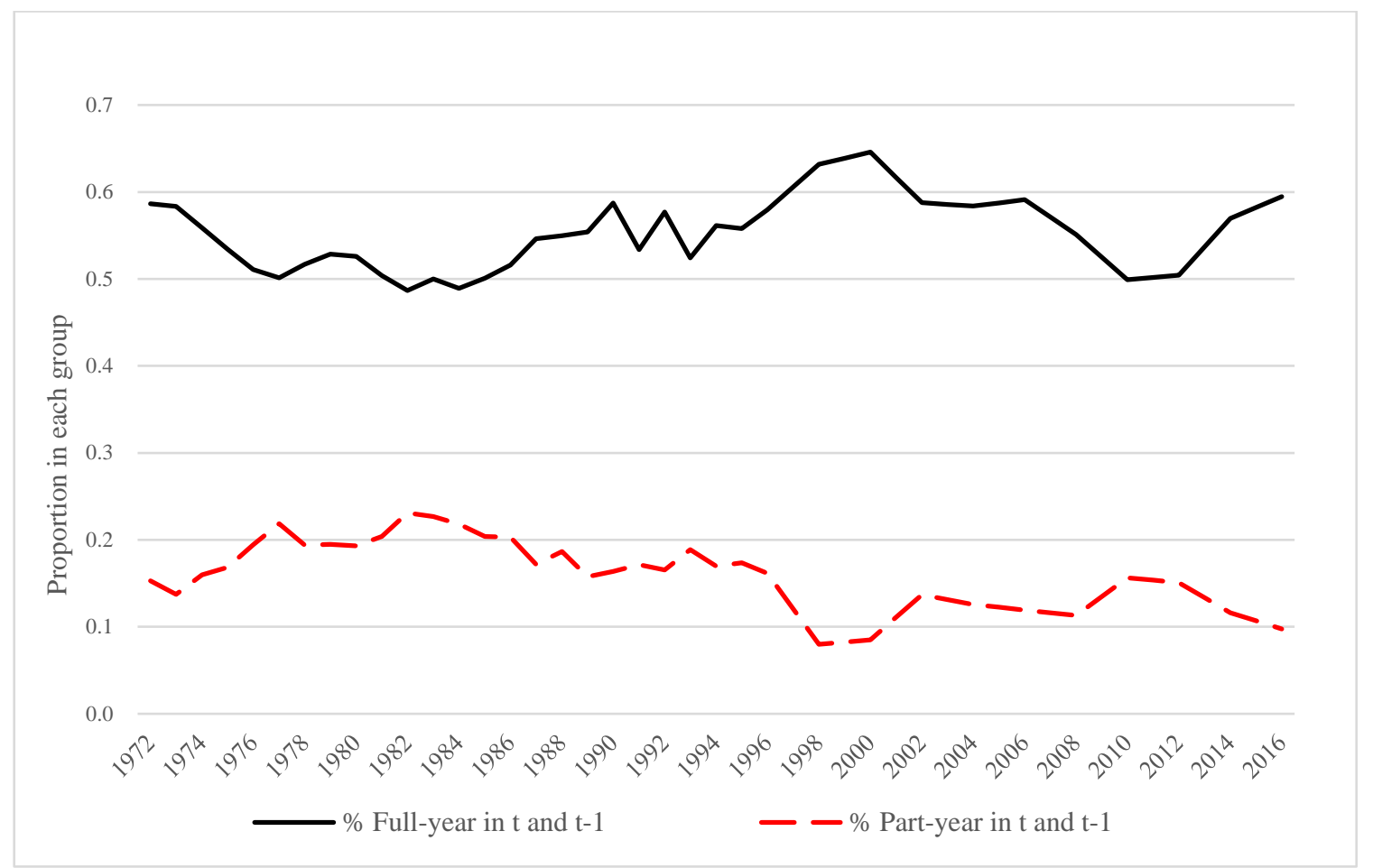

Figure 7b: Values of Ng/N for workers who are full-year and part-year in both years 


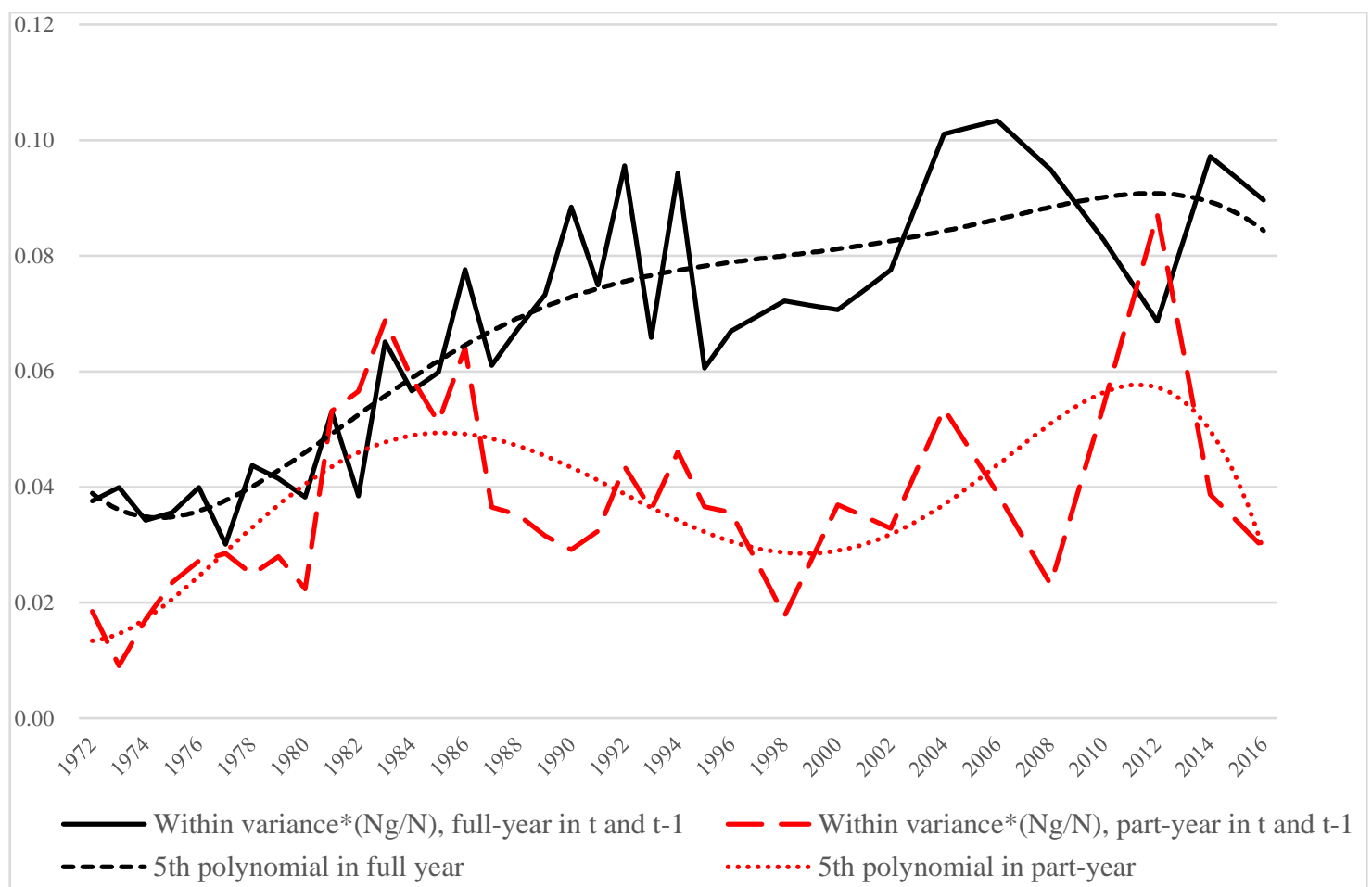

Figure 7c: Within group variance* $(\mathrm{Ng} / \mathrm{N})$ for workers who are full-year or part-year in both years 


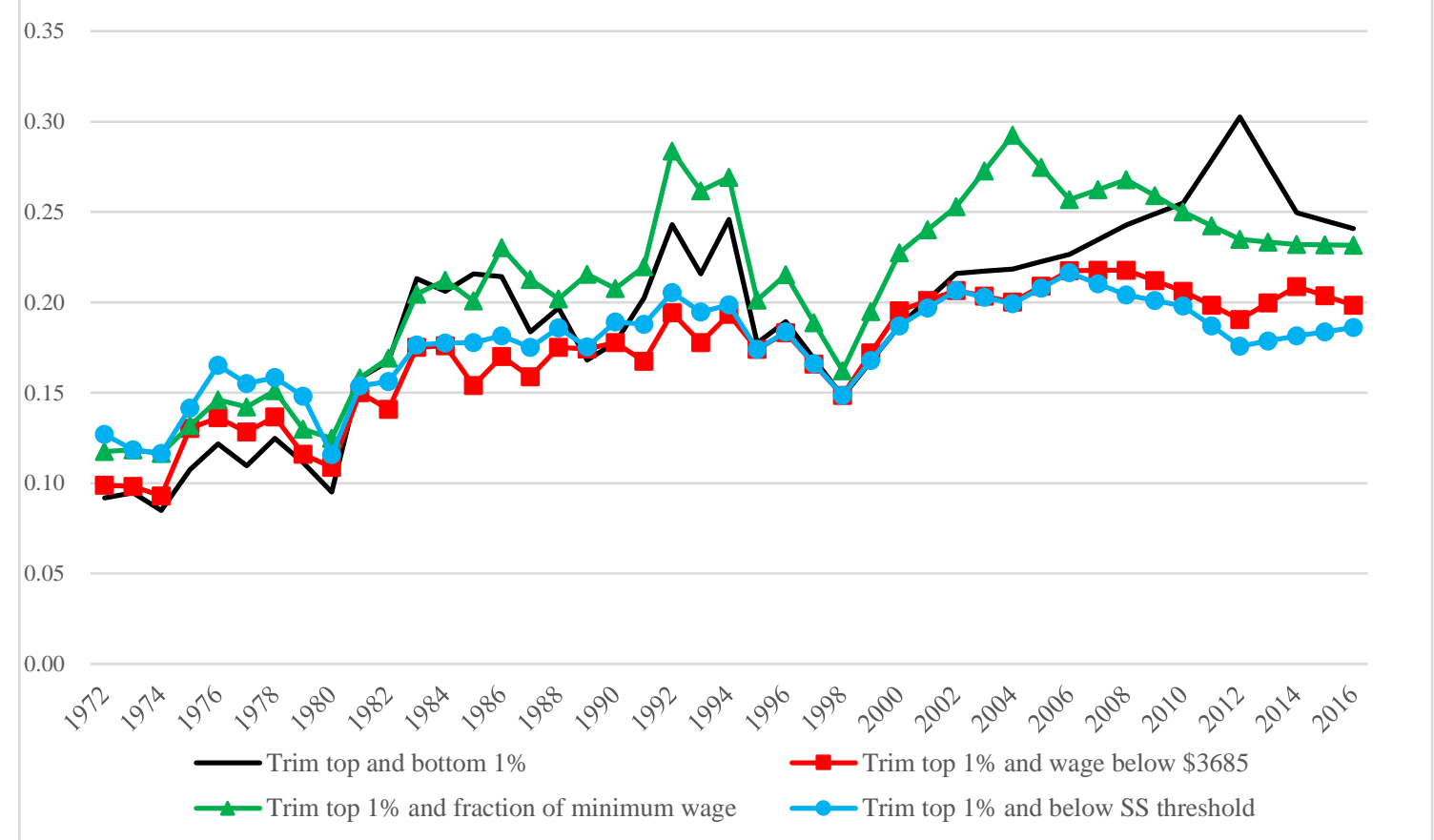

Figure 8a: Variance in 2-year difference in log earnings residuals, different trimming at the bottom

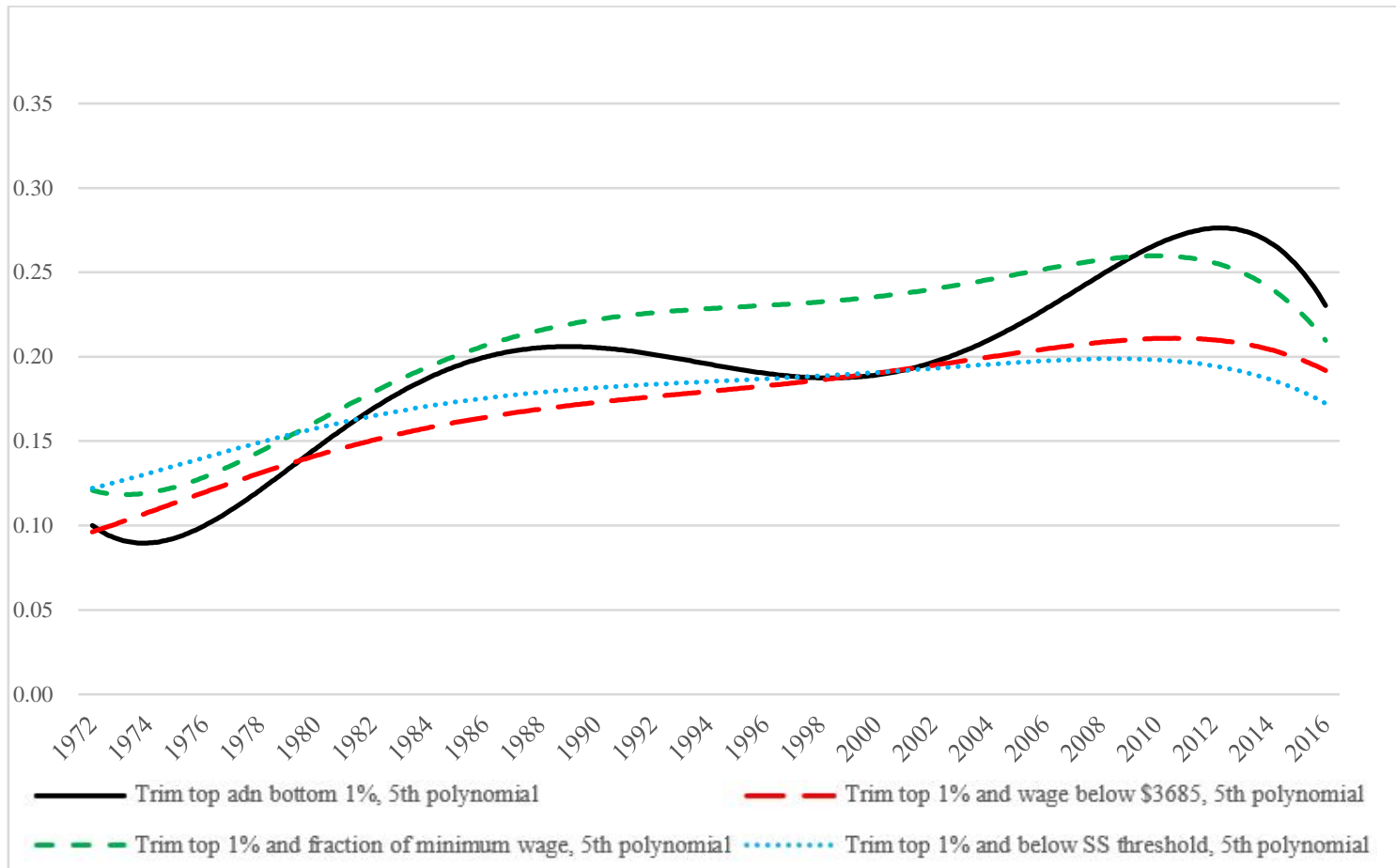

Figure 8b: Variance in 2-year difference in log earnings residuals, different trimming at the bottom, 5th polynomial 


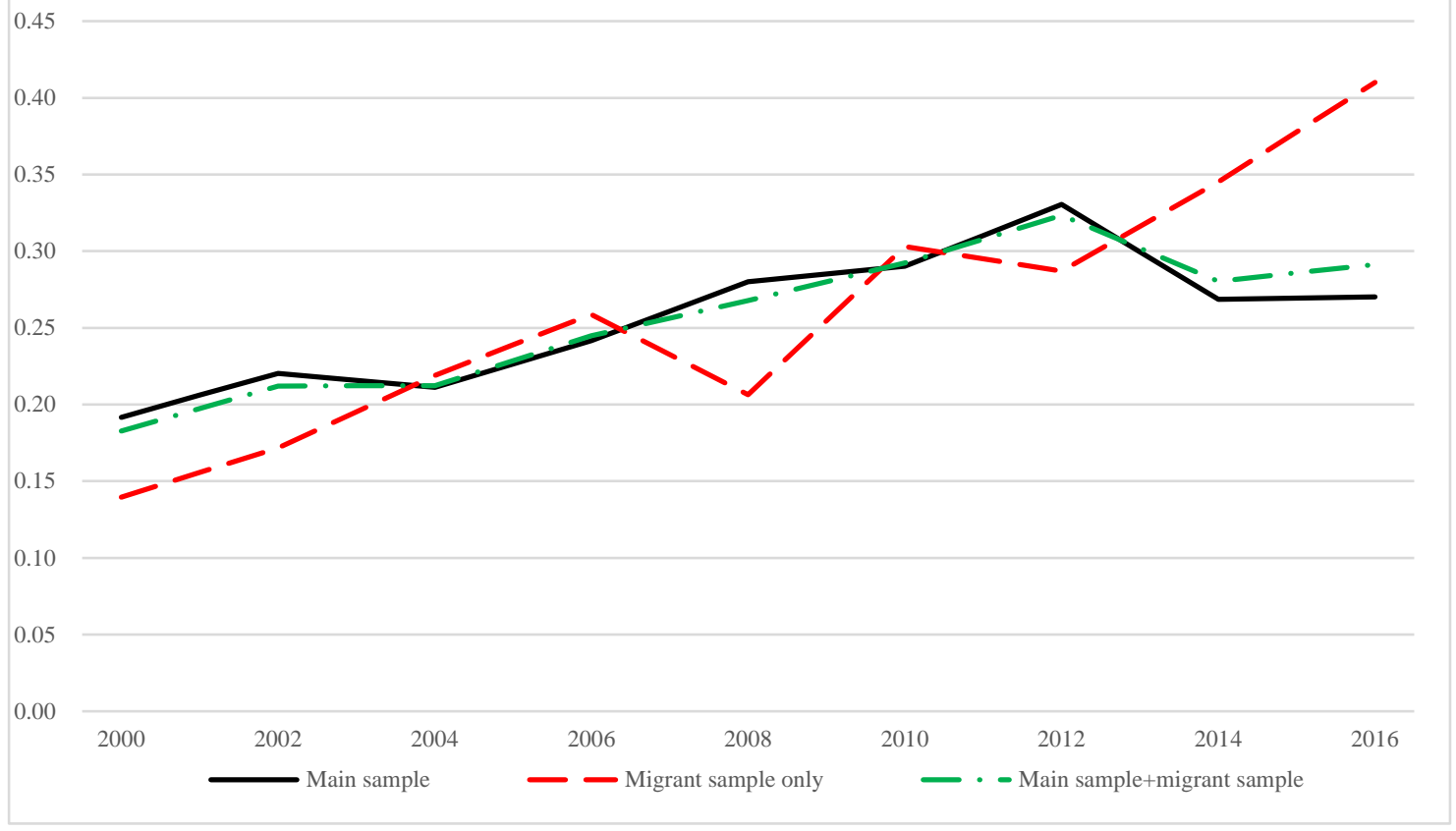

Figure 9: Variance in 2-year difference in log earnings residuals, excluding or including immigrant sample, or immigrant sample only 
Appendix Table 1: Real mean earnings, percentile points and variance

\begin{tabular}{|c|c|c|c|c|c|c|c|c|}
\hline & $\begin{array}{r}\text { Real } \\
\text { Mean } \\
\text { Earnings }\end{array}$ & $\begin{array}{r}\text { 10th } \\
\text { Percentile }\end{array}$ & $\begin{array}{r}\text { 25th } \\
\text { Percentile }\end{array}$ & Median & $\begin{array}{r}\text { 75th } \\
\text { Percentile }\end{array}$ & $\begin{array}{r}\text { 90th } \\
\text { Percentile }\end{array}$ & $\begin{array}{r}\text { Variance } \\
\text { of log } \\
\text { earnings }\end{array}$ & $\begin{array}{r}\text { Coefficient } \\
\text { of } \\
\text { variation }\end{array}$ \\
\hline 1970 & 47,637 & 22,840 & 31,976 & 44,310 & 58,992 & 76,743 & 0.264 & 0.485 \\
\hline 1971 & 48,451 & 22,786 & 32,864 & 44,290 & 61,347 & 76,683 & 0.290 & 0.489 \\
\hline 1972 & 50,211 & 24,979 & 33,899 & 46,611 & 61,442 & 80,510 & 0.242 & 0.469 \\
\hline 1973 & 51,899 & 24,929 & 36,188 & 48,251 & 63,932 & 80,418 & 0.224 & 0.455 \\
\hline 1974 & 49,530 & 21,850 & 33,326 & 47,343 & 61,910 & 80,118 & 0.258 & 0.466 \\
\hline 1975 & 48,993 & 22,859 & 33,213 & 45,382 & 60,509 & 80,679 & 0.275 & 0.492 \\
\hline 1976 & 50,440 & 22,307 & 32,926 & 47,802 & 63,417 & 82,856 & 0.313 & 0.508 \\
\hline 1977 & 50,960 & 23,338 & 34,409 & 47,873 & 62,834 & 80,786 & 0.273 & 0.483 \\
\hline 1978 & 52,312 & 23,882 & 34,969 & 50,075 & 64,342 & 81,127 & 0.261 & 0.495 \\
\hline 1979 & 51,560 & 23,637 & 34,299 & 48,815 & 63,928 & 82,214 & 0.283 & 0.488 \\
\hline 1980 & 50,591 & 23,194 & 32,646 & 46,389 & 62,625 & 81,181 & 0.284 & 0.507 \\
\hline 1981 & 49,775 & 19,585 & 31,931 & 46,833 & 61,734 & 80,893 & 0.365 & 0.528 \\
\hline 1982 & 48,298 & 18,150 & 30,251 & 46,142 & 60,501 & 80,668 & 0.436 & 0.547 \\
\hline 1983 & 48,831 & 17,990 & 30,951 & 46,427 & 62,336 & 81,247 & 0.481 & 0.541 \\
\hline 1984 & 50,748 & 19,106 & 30,943 & 46,974 & 65,241 & 85,745 & 0.411 & 0.551 \\
\hline 1985 & 51,116 & 18,012 & 30,620 & 46,831 & 66,644 & 88,259 & 0.471 & 0.590 \\
\hline 1986 & 51,504 & 17,981 & 31,246 & 47,597 & 66,988 & 89,905 & 0.472 & 0.575 \\
\hline 1987 & 52,519 & 19,666 & 31,637 & 47,434 & 66,695 & 90,653 & 0.383 & 0.564 \\
\hline 1988 & 52,756 & 18,927 & 31,270 & 47,728 & 67,478 & 93,317 & 0.432 & 0.585 \\
\hline 1989 & 51,901 & 18,923 & 31,539 & 46,993 & 66,547 & 91,463 & 0.432 & 0.594 \\
\hline 1990 & 52,187 & 19,638 & 30,212 & 45,587 & 66,467 & 90,637 & 0.433 & 0.620 \\
\hline 1991 & 52,022 & 18,857 & 30,697 & 45,314 & 67,240 & 89,167 & 0.474 & 0.609 \\
\hline 1992 & 54,356 & 19,184 & 32,747 & 48,409 & 70,478 & 93,505 & 0.501 & 0.605 \\
\hline 1993 & 54,986 & 20,837 & 31,950 & 47,232 & 69,042 & 97,241 & 0.438 & 0.664 \\
\hline 1994 & 54,233 & 19,051 & 31,298 & 47,629 & 68,041 & 96,619 & 0.459 & 0.636 \\
\hline 1995 & 54,524 & 19,990 & 31,984 & 46,644 & 69,298 & 99,747 & 0.452 & 0.650 \\
\hline 1996 & 55,736 & 22,182 & 32,621 & 45,671 & 71,768 & 103,085 & 0.394 & 0.629 \\
\hline 1998 & 60,381 & 22,903 & 34,355 & 50,896 & 76,344 & 108,154 & 0.400 & 0.635 \\
\hline 2000 & 63,799 & 23,243 & 35,821 & 51,379 & 78,291 & 119,884 & 0.450 & 0.707 \\
\hline 2002 & 60,678 & 21,323 & 33,170 & 49,754 & 77,001 & 112,540 & 0.489 & 0.708 \\
\hline 2004 & 62,478 & 20,748 & 32,880 & 51,021 & 75,964 & 119,049 & 0.520 & 0.745 \\
\hline 2006 & 65,302 & 22,538 & 32,412 & 51,515 & 77,810 & 123,422 & 0.511 & 0.809 \\
\hline 2008 & 61,326 & 20,324 & 32,440 & 50,810 & 76,824 & 117,878 & 0.560 & 0.755 \\
\hline 2010 & 59,879 & 18,000 & 31,100 & 50,000 & 75,000 & 114,000 & 0.628 & 0.743 \\
\hline 2012 & 60,422 & 17,227 & 29,956 & 48,810 & 76,564 & 116,760 & 0.777 & 0.790 \\
\hline 2014 & 61,543 & 18,607 & 32,191 & 50,240 & 79,081 & 111,644 & 0.616 & 0.749 \\
\hline 2016 & 63,182 & 20,761 & 33,054 & 51,417 & 78,044 & 120,528 & 0.583 & 0.724 \\
\hline
\end{tabular}


Appendix Table 2: Mean and percentile points of 2-year difference in real earnings

\begin{tabular}{|c|c|c|c|c|c|c|}
\hline & $\begin{array}{r}\text { Mean in } \\
\text { Difference of } \\
\text { Earnings }\end{array}$ & $\begin{array}{r}\text { 10th } \\
\text { Percentile }\end{array}$ & $\begin{array}{r}\text { 25th } \\
\text { Percentile }\end{array}$ & Median & $\begin{array}{r}\text { 75th } \\
\text { Percentile }\end{array}$ & $\begin{array}{r}90 \text { th } \\
\text { Percentile }\end{array}$ \\
\hline 1972 & 3,524 & $-8,267$ & $-2,306$ & 2,632 & 8,810 & 16,557 \\
\hline 1973 & 4,905 & $-7,503$ & $-1,394$ & 3,759 & 9,864 & 18,349 \\
\hline 1974 & -25 & $-13,539$ & $-5,888$ & 170 & 5,565 & 11,475 \\
\hline 1975 & $-2,513$ & $-16,757$ & $-8,904$ & $-1,806$ & 3,590 & 11,070 \\
\hline 1976 & 1,634 & $-11,789$ & $-3,633$ & 920 & 7,200 & 15,938 \\
\hline 1977 & 3,423 & $-8,655$ & $-2,181$ & 2,723 & 9,364 & 17,804 \\
\hline 1978 & 2,961 & $-9,913$ & $-2,787$ & 2,185 & 8,013 & 18,913 \\
\hline 1979 & 2,415 & $-11,234$ & $-4,213$ & 1,550 & 8,437 & 16,779 \\
\hline 1980 & -481 & $-15,747$ & $-5,807$ & -405 & 5,648 & 12,758 \\
\hline 1981 & -864 & $-16,002$ & $-6,606$ & -294 & 5,102 & 14,681 \\
\hline 1982 & $-1,471$ & $-18,155$ & $-6,055$ & -306 & 5,240 & 12,701 \\
\hline 1983 & 857 & $-14,344$ & $-4,440$ & 1,149 & 6,792 & 16,430 \\
\hline 1984 & 3,524 & $-10,527$ & $-2,106$ & 3,028 & 10,453 & 19,113 \\
\hline 1985 & 3,867 & $-11,977$ & $-2,463$ & 2,978 & 9,675 & 18,899 \\
\hline 1986 & 2,374 & $-14,885$ & $-3,722$ & 2,104 & 9,111 & 18,232 \\
\hline 1987 & 3,085 & $-11,687$ & $-2,469$ & 2,489 & 9,499 & 19,988 \\
\hline 1988 & 2,576 & $-11,850$ & $-3,236$ & 2,002 & 9,003 & 18,828 \\
\hline 1989 & 1,147 & $-14,731$ & $-5,055$ & 358 & 7,289 & 16,414 \\
\hline 1990 & -182 & $-15,633$ & $-5,347$ & 102 & 5,684 & 14,783 \\
\hline 1991 & 624 & $-13,768$ & $-4,298$ & 584 & 6,287 & 15,165 \\
\hline 1992 & 3,965 & $-11,377$ & $-3,347$ & 1,875 & 9,741 & 21,944 \\
\hline 1993 & 3,680 & $-12,026$ & $-2,860$ & 1,850 & 8,682 & 20,678 \\
\hline 1994 & 2,355 & $-16,869$ & $-4,509$ & 1,229 & 8,753 & 23,478 \\
\hline 1995 & 2,288 & $-15,868$ & $-3,855$ & 1,835 & 8,785 & 18,338 \\
\hline 1996 & 2,275 & $-15,287$ & $-3,339$ & 2,348 & 9,617 & 20,224 \\
\hline 1998 & 6,080 & $-10,595$ & $-1,623$ & 4,242 & 13,256 & 26,175 \\
\hline 2000 & 3,415 & $-17,028$ & $-3,335$ & 3,175 & 11,190 & 25,337 \\
\hline 2002 & 441 & $-21,352$ & $-5,912$ & 798 & 8,070 & 21,895 \\
\hline 2004 & 2,658 & $-17,723$ & $-4,144$ & 1,352 & 9,074 & 24,245 \\
\hline 2006 & 3,723 & $-17,750$ & $-4,915$ & 1,348 & 10,275 & 24,843 \\
\hline 2008 & 462 & $-20,146$ & $-6,222$ & 785 & 7,818 & 22,998 \\
\hline 2010 & -598 & $-21,943$ & $-6,457$ & 374 & 7,705 & 20,174 \\
\hline 2012 & 2,585 & $-16,503$ & $-4,939$ & 368 & 7,911 & 21,349 \\
\hline 2014 & 4,132 & $-12,842$ & $-2,981$ & 2,754 & 11,077 & 23,839 \\
\hline 2016 & 4,531 & $-14,196$ & $-2,385$ & 3,533 & 11,561 & 24,339 \\
\hline
\end{tabular}




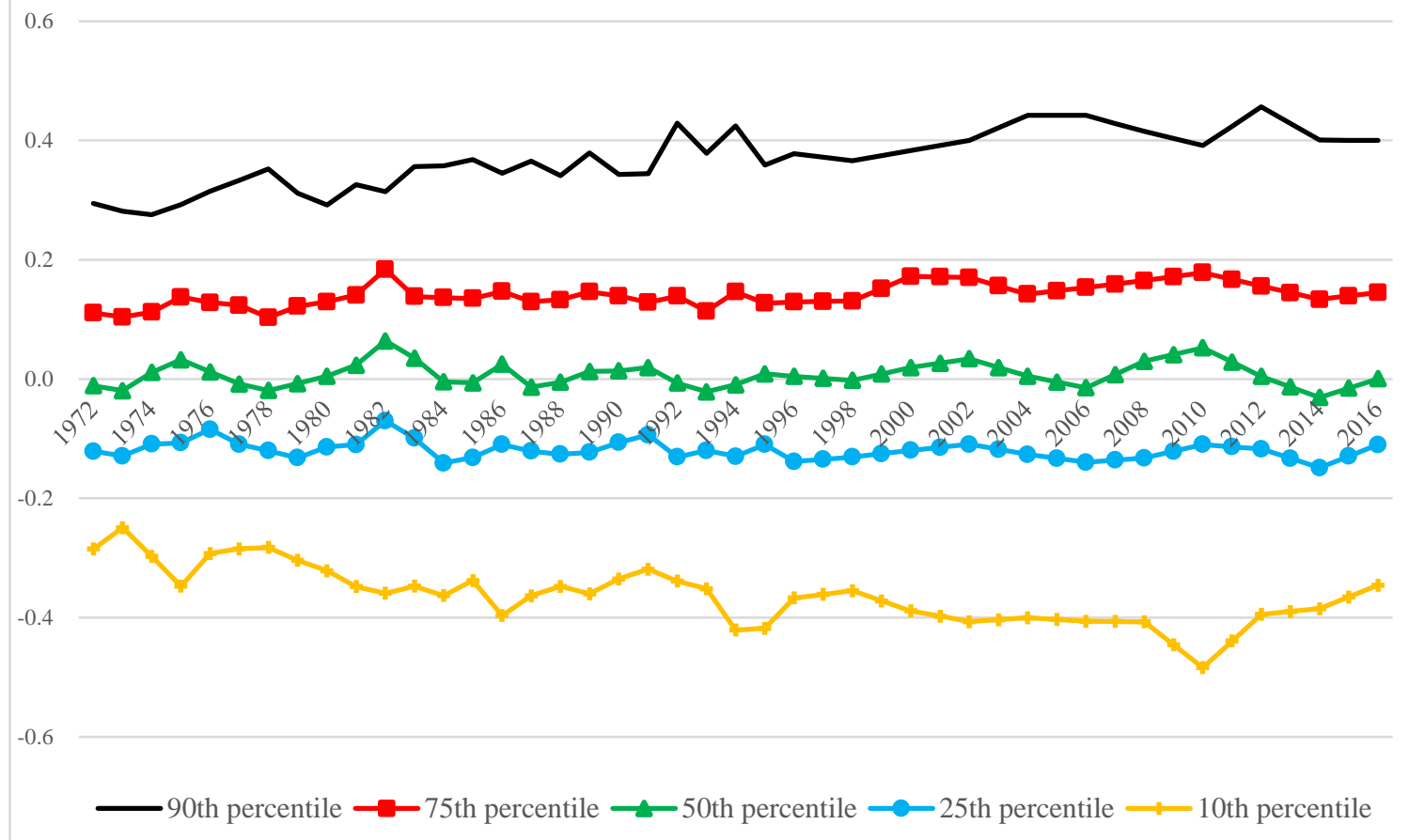

Appendix Figure 1: Percentile points in 2-year difference in log earnings residuals 


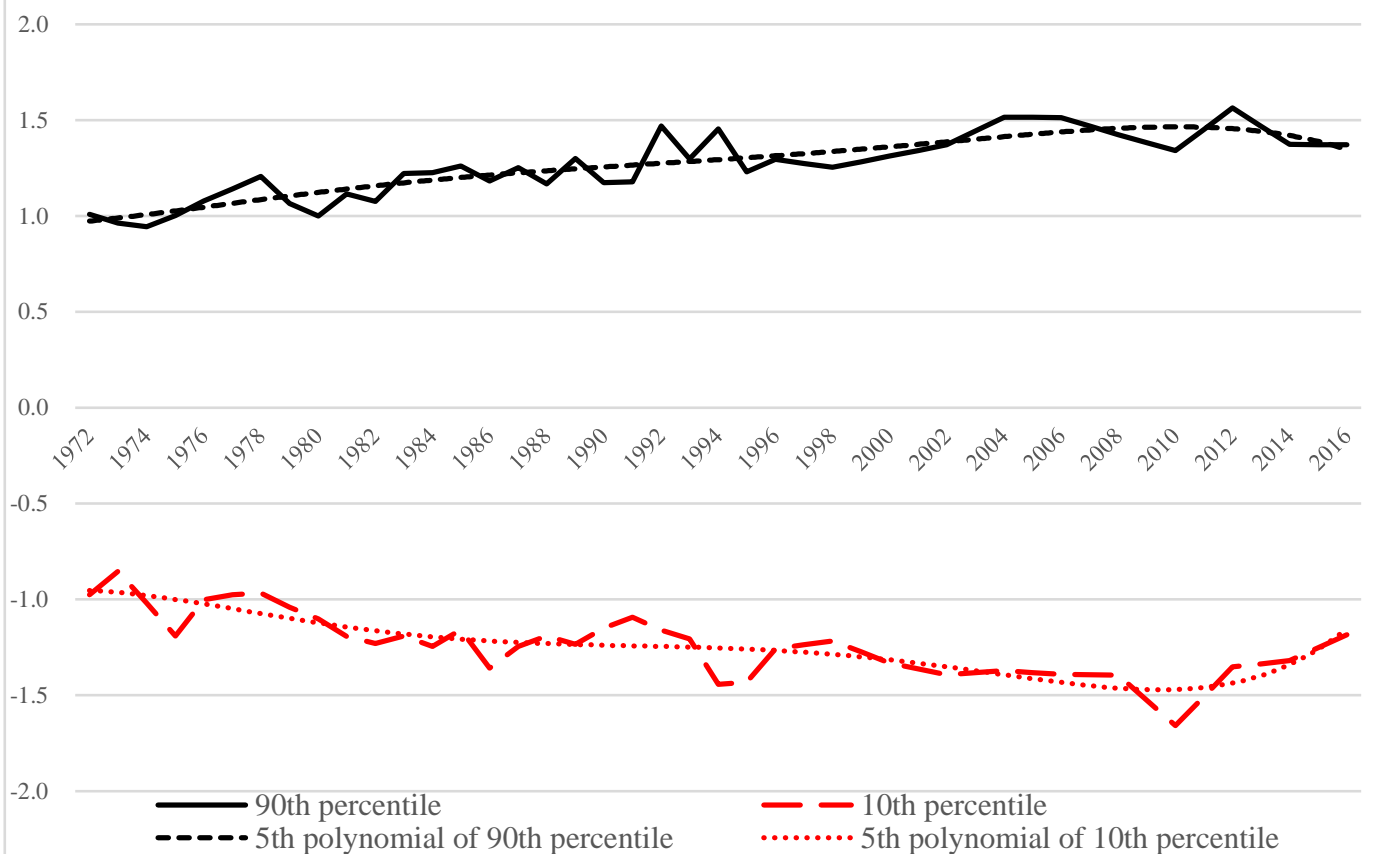

Appendix Figure 2a: Percentile points in 2-year difference in log earnings residuals, 1972-76=1

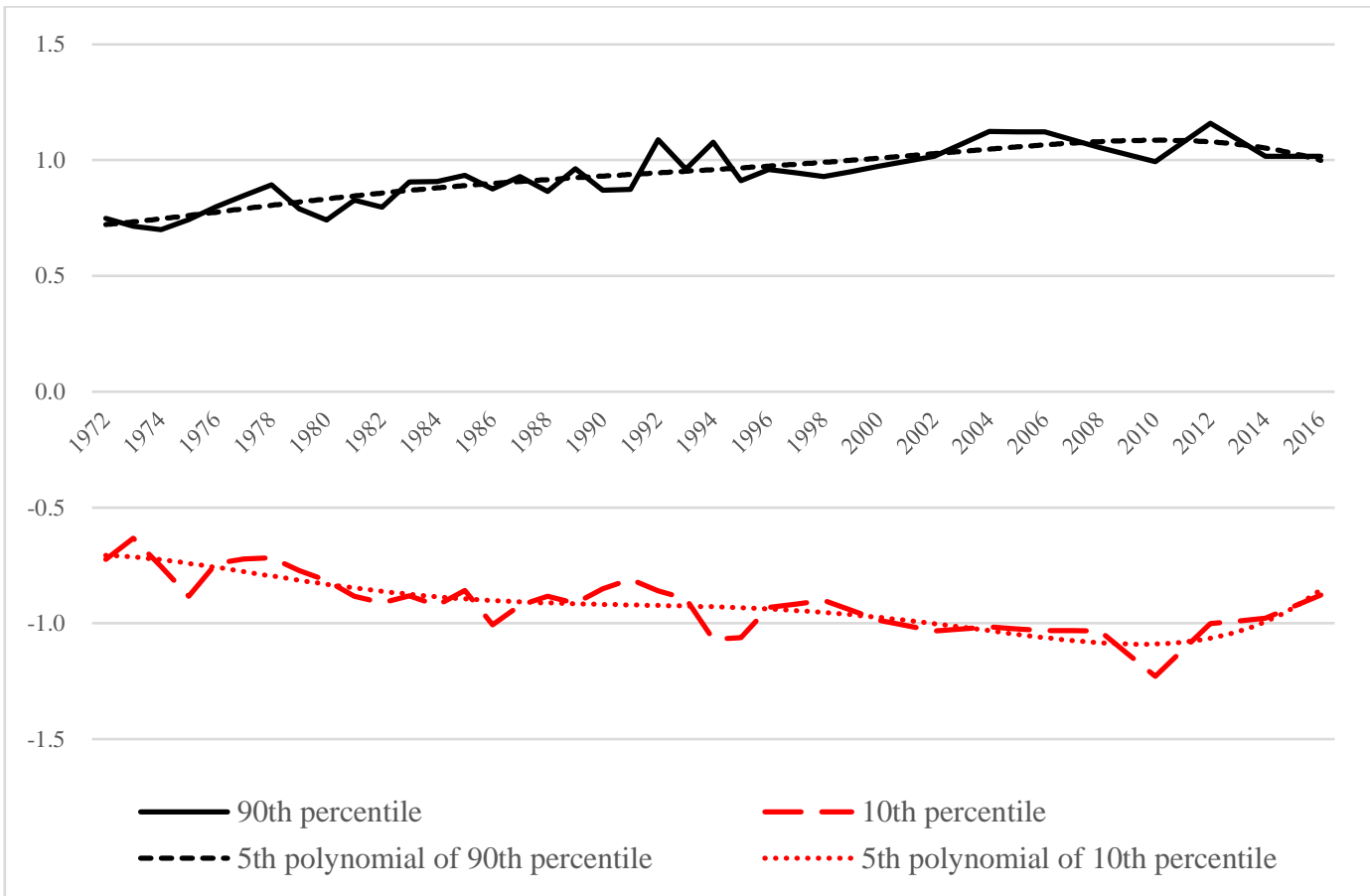

Appendix Figure 2b: Percentile Points in 2-year difference in Log earnings residuals, 1992-96=1 


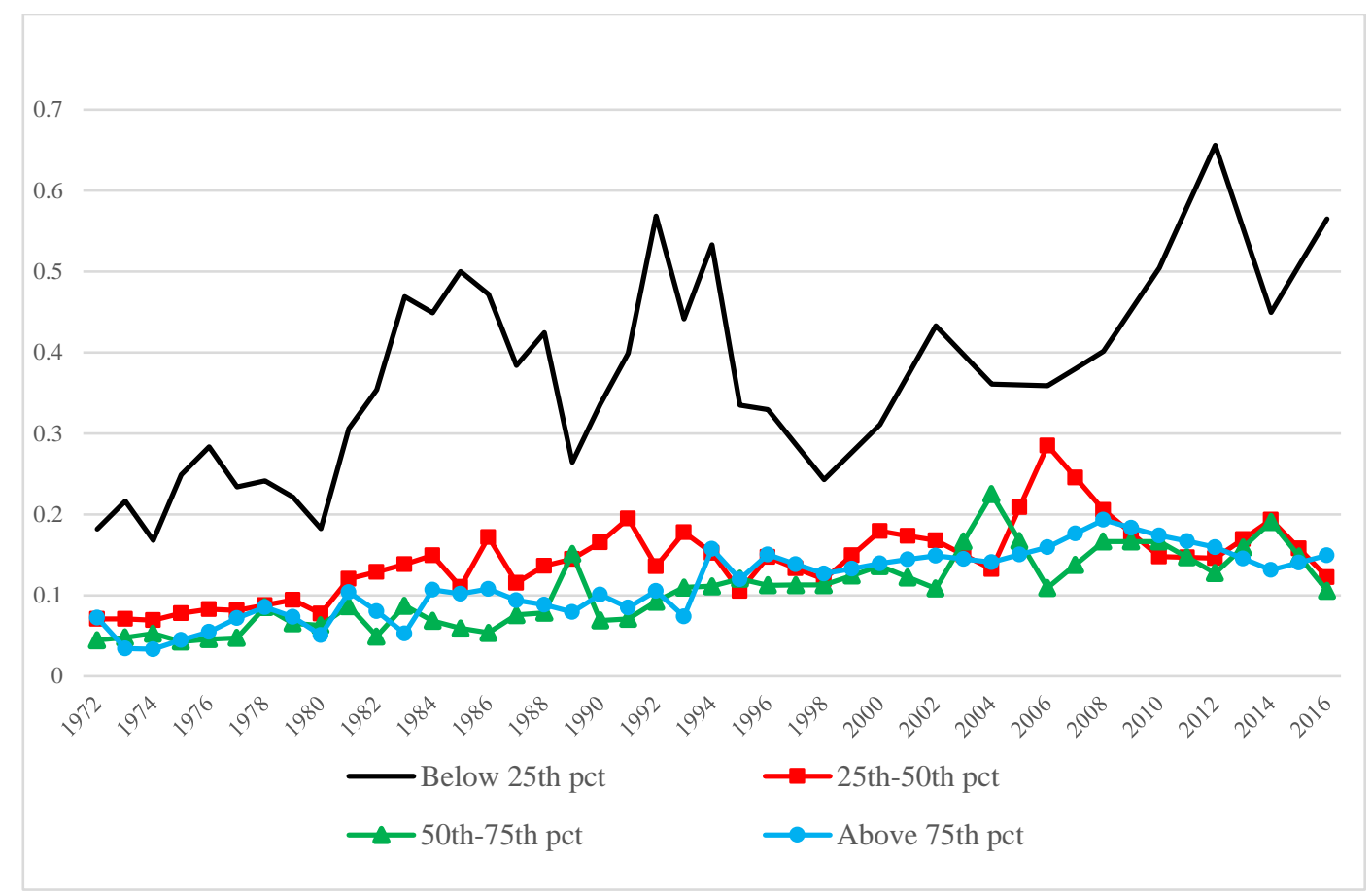

Appendix Figure 3: Variance in 2-year difference in log real earnings by quartile, unnormed 


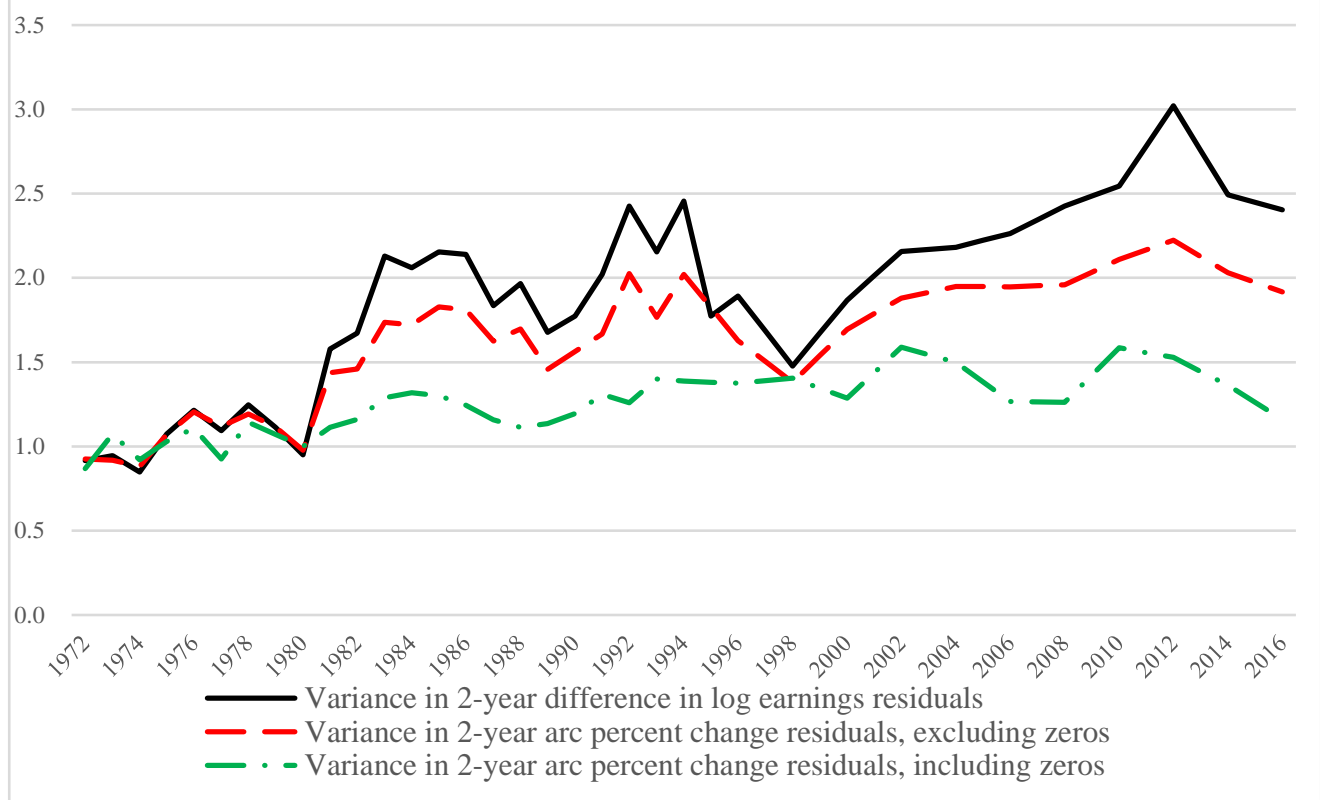

Appendix Figure 4a: Variance in 2-year difference in residuals of log earnings, arc percent change excluding zeros, and arc percent change including zeros, 1972-76=1

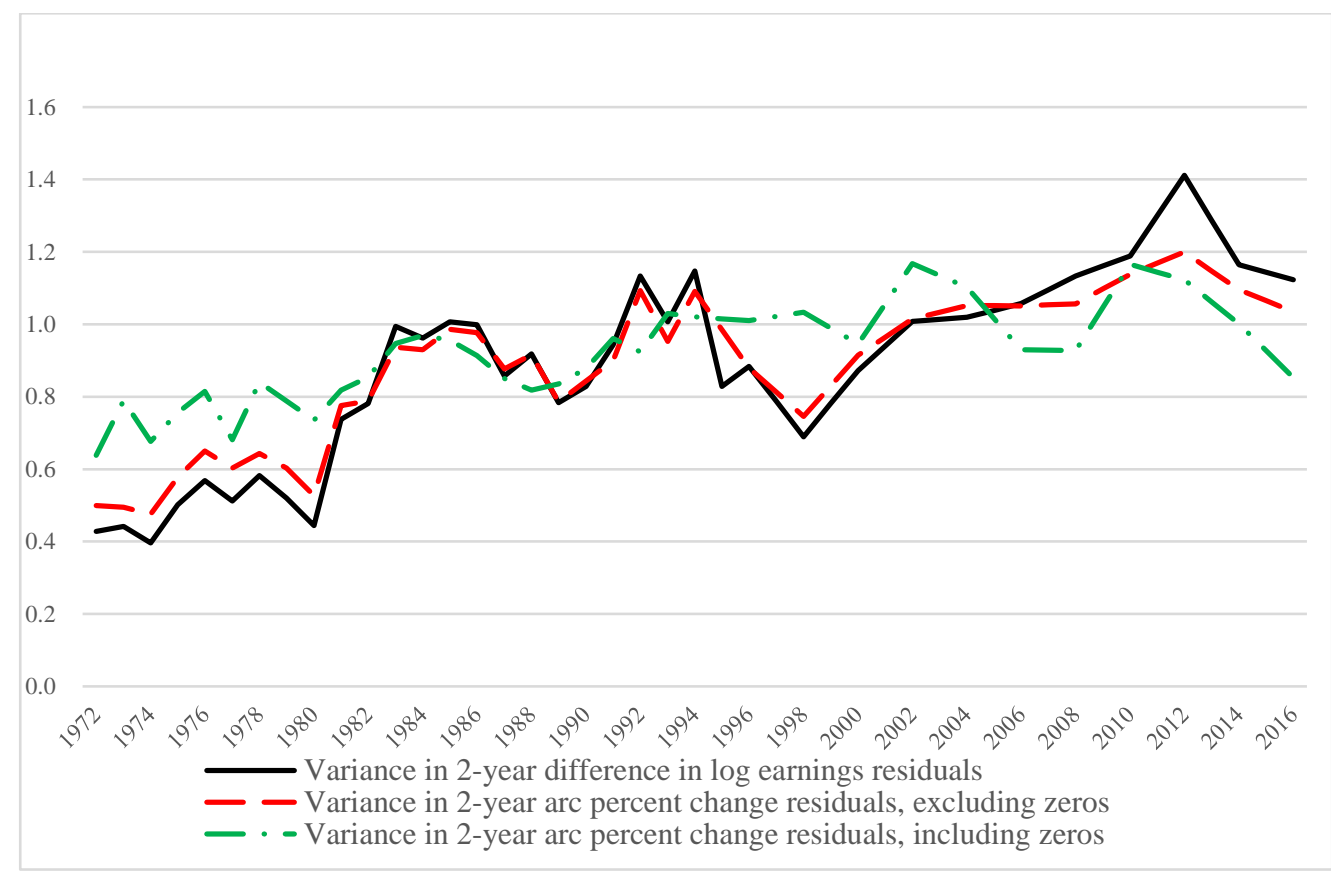

Appendix Figure 4b: Variance in 2-year difference in residuals of log earnings, arc percent change excluding zeros, and arc percent change including zeros, 1992-96=1 


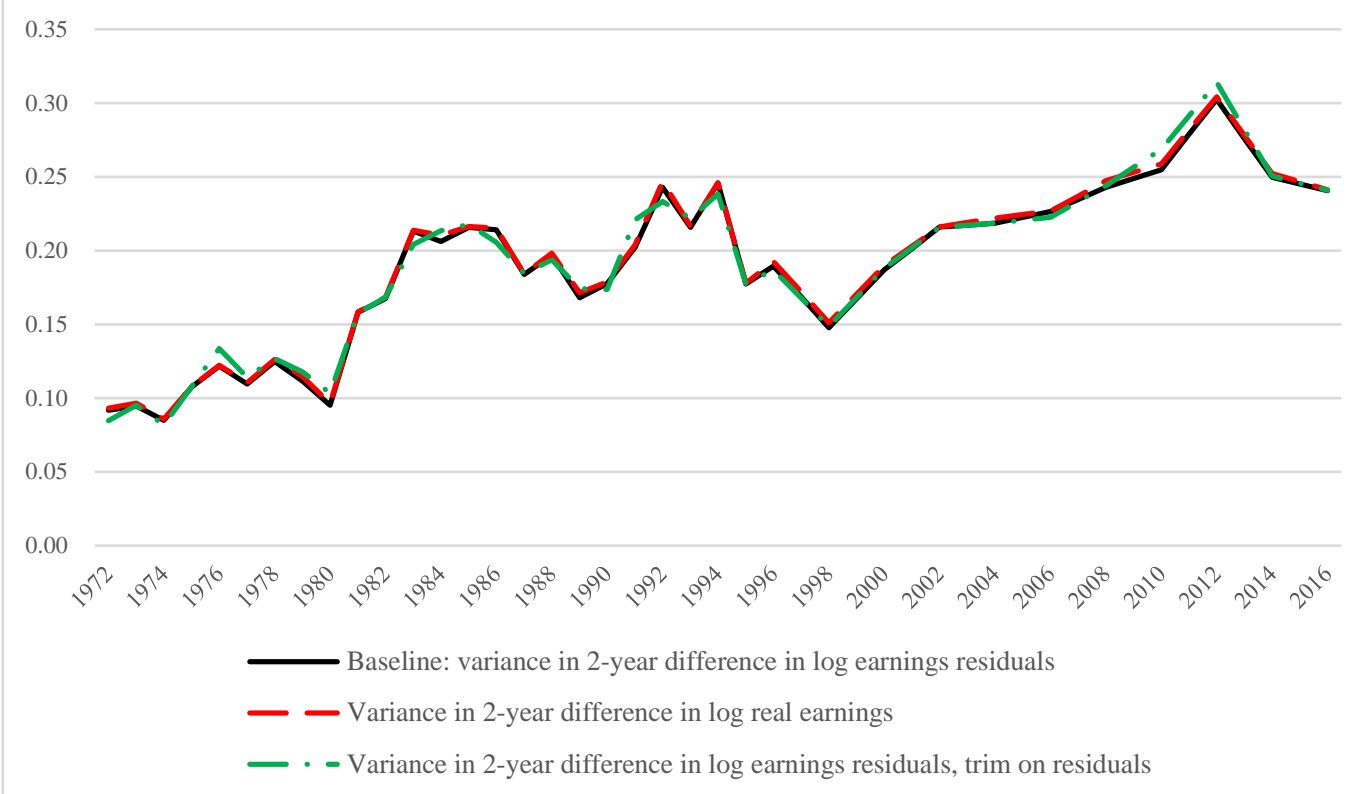

Appendix Figure 5: variance in 2-year difference in log real earnings or residuals, and trim on log real earnings or residuals

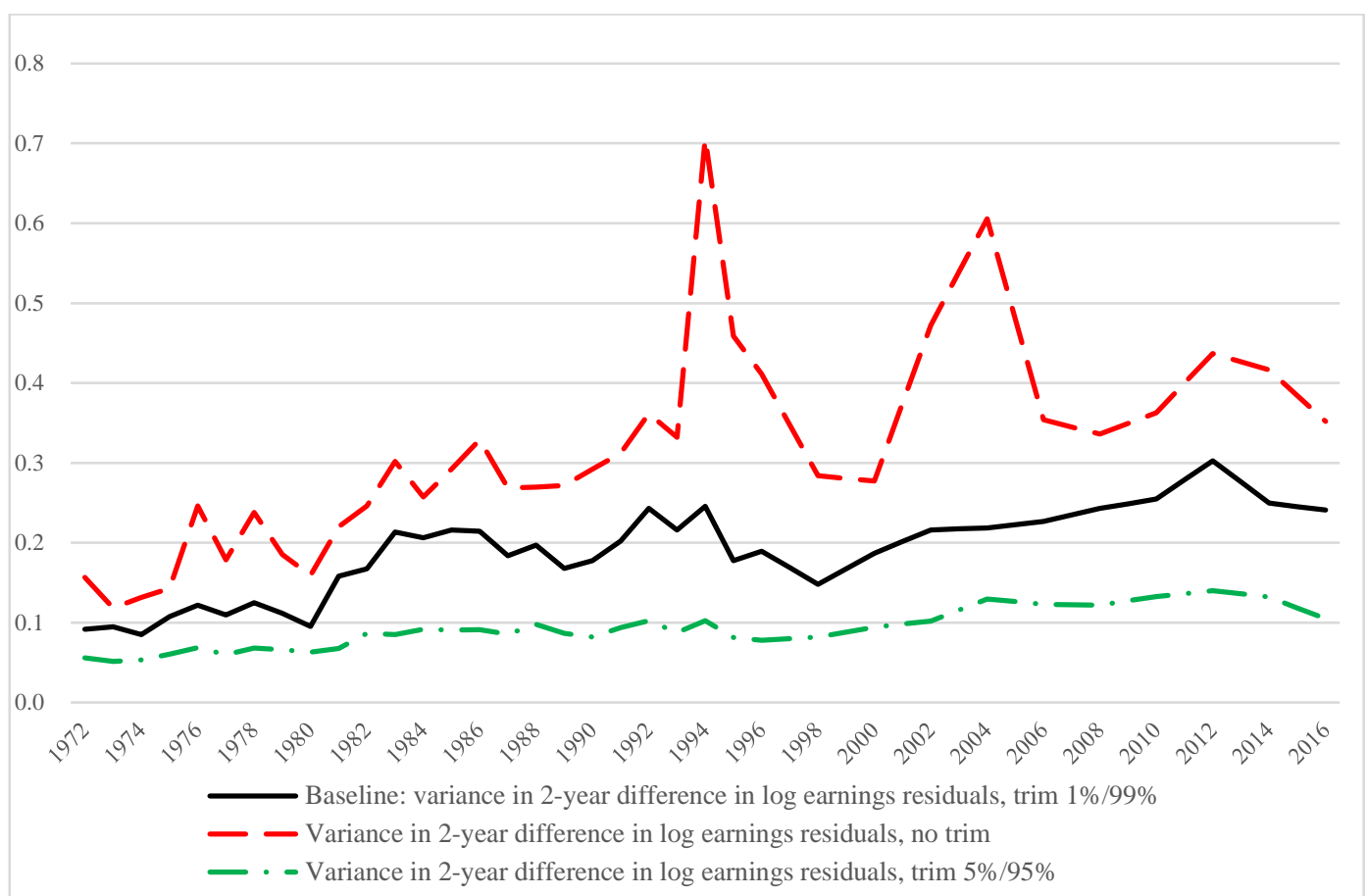

Appendix Figure 6: variance in 2-year difference in log earnings residuals, no trim, trim $1 \% / 99 \%$, or trim $5 \% / 95 \%$ 


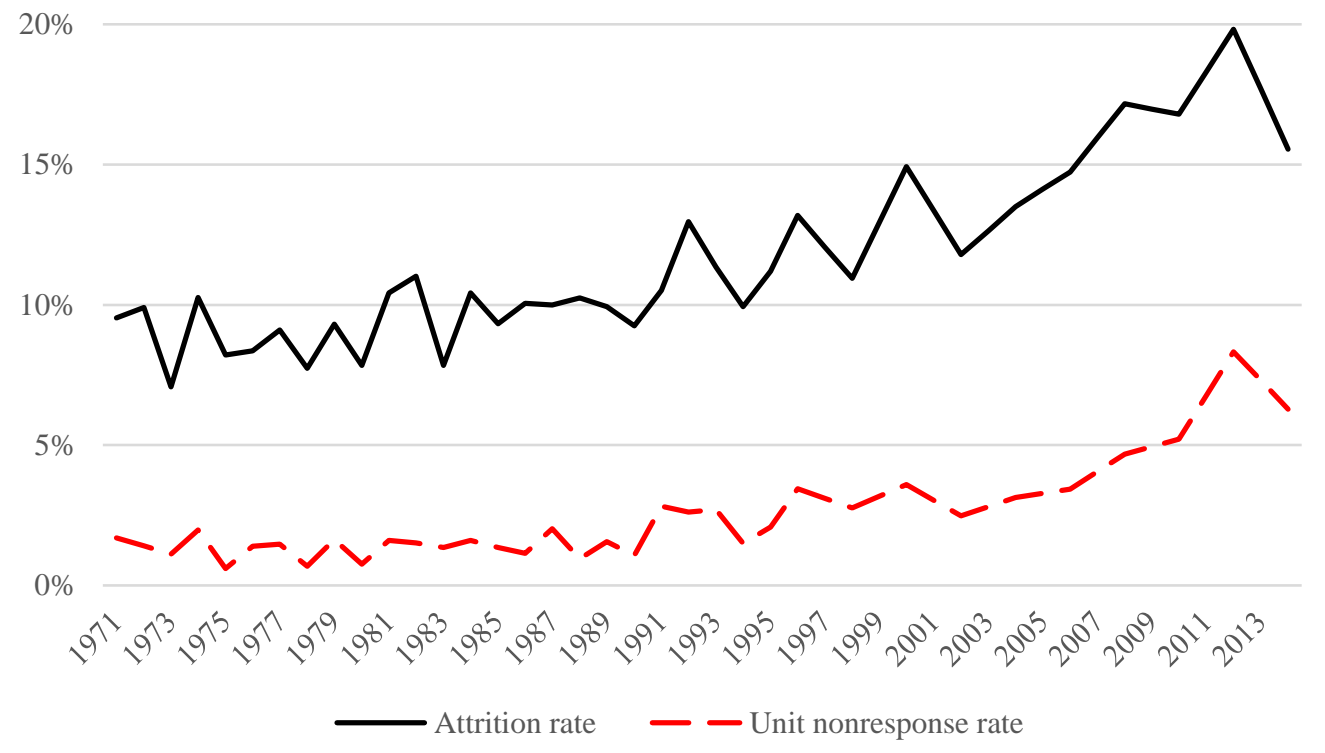

Appendix Figure 7: Attrition rate year-by-year in analysis sample

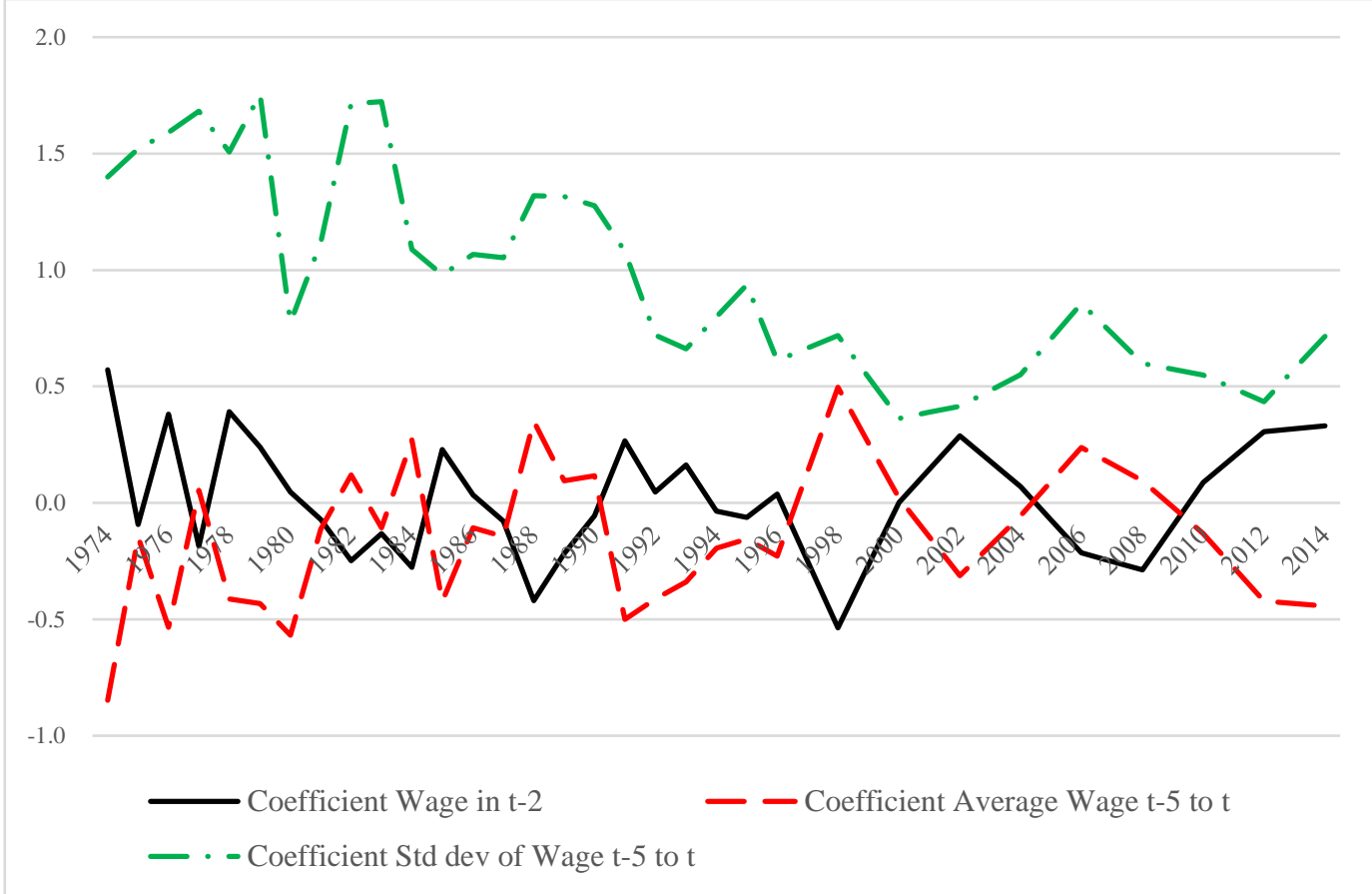

Appendix Figure 8: Coefficients in lag earnings, mean earnings and std of earnings over past six years 